Atmos. Chem. Phys., 19, 10739-10755, 2019

https://doi.org/10.5194/acp-19-10739-2019

(C) Author(s) 2019. This work is distributed under

the Creative Commons Attribution 4.0 License.

\title{
Core and margin in warm convective clouds - Part 2: Aerosol effects on core properties
}

\author{
Reuven H. Heiblum ${ }^{1}$, Lital Pinto ${ }^{1}$, Orit Altaratz ${ }^{1}$, Guy Dagan $^{1, a}$, and Ilan Koren ${ }^{1}$ \\ ${ }^{1}$ Department of Earth and Planetary Sciences, Weizmann Institute of Science, Rehovot, Israel \\ anow at: Atmospheric, Oceanic and Planetary Physics, Department of Physics, University of Oxford, Oxford, UK
}

Correspondence: Ilan Koren (ilan.koren@weizmann.ac.il)

Received: 29 July 2018 - Discussion started: 30 August 2018

Revised: 10 June 2019 - Accepted: 18 July 2019 - Published: 26 August 2019

\begin{abstract}
The effects of aerosol on warm convective cloud cores are evaluated using single cloud and cloud field simulations. Three core definitions are examined: positive vertical velocity ( $\left.W_{\text {core }}\right)$, supersaturation $\left(\mathrm{RH}_{\text {core }}\right)$, and positive buoyancy $\left(B_{\text {core }}\right)$. As presented in Part 1 (Heiblum et al., 2019), the property $B_{\text {core }} \subseteq \mathrm{RH}_{\text {core }} \subseteq W_{\text {core }}$ is seen during growth of warm convective clouds. We show that this property is kept irrespective of aerosol concentration. During dissipation core fractions generally decrease with less overlap between cores. However, for clouds that develop in low aerosol concentrations capable of producing precipitation, $B_{\text {core }}$ and subsequently $W_{\text {core }}$ volume fractions may increase during dissipation (i.e., loss of cloud mass). $\mathrm{The}^{\mathrm{RH}} \mathrm{H}_{\text {core }}$ volume fraction decreases during cloud lifetime and shows minor sensitivity to aerosol concentration.

It is shown that a $B_{\text {core }}$ forms due to two processes: (i) convective updrafts - condensation within supersaturated updrafts and release of latent heat - and (ii) dissipative downdrafts - subsaturated cloudy downdrafts that warm during descent and "undershoot" the level of neutral buoyancy. The former process occurs during cloud growth for all aerosol concentrations. The latter process only occurs for low aerosol concentrations during dissipation and precipitation stages where large mean drop sizes permit slow evaporation rates and subsaturation during descent.

The aerosol effect on the diffusion efficiencies plays a crucial role in the development of the cloud and its partition to core and margin. Using the $\mathrm{RH}_{\text {core }}$ definition, it is shown that the total cloud mass is mostly dictated by core processes, while the total cloud volume is mostly dictated by margin processes. Increase in aerosol concentration increases the core (mass and volume) due to enhanced condensation but
\end{abstract}

also decreases the margin due to evaporation. In clean clouds larger droplets evaporate much slower, enabling preservation of cloud size, and even increase by detrainment and dilution (volume increases while losing mass). This explains how despite having smaller cores and less mass, cleaner clouds may live longer and grow to larger sizes.

\section{Introduction}

Aerosols remain one of the largest sources of uncertainty in climate predictions, mainly via their effects on clouds (IPCC, 2013). Here we focus on the aerosol effects on warm clouds. Aerosols act as cloud condensation nuclei (CCN) during heterogeneous nucleation of cloud droplets (Köhler, 1936; Mason and Chien, 1962). The number, size, and composition of an aerosol distribution determine the initial cloud droplet size distribution (DSD). Polluted clouds (i.e., more aerosols) have more but smaller droplets and a narrower DSD compared to clean clouds (Andreae et al., 2004; Twomey, 1977). Changes in the initial DSD drive various effects and feedbacks on the cloud's evolution and key processes, such as droplet mobility, condensation-evaporation budgets, collision-coalescence, and entrainment (Jiang et al., 2006; Koren et al., 2015; Small et al., 2009; Xue and Feingold, 2006).

It is well known that an abundance of small droplets in a cloud (a narrow DSD) reduces the efficiency of the collisioncoalescence process (Squires, 1958; Twomey, 1977; Warner, 1968), prolongs the diffusional growth time (Khain et al., 2005; Wang, 2005), and delays or even completely suppresses the initiation of precipitation (Albrecht, 1989; Hud- 
son and Mishra, 2007; Hudson and Yum, 2001; L'Ecuyer et al., 2009). Moreover, in-cloud condensational growth is more efficient in consuming supersaturation because of the larger surface-area-to-volume ratio of droplets (Dagan et al., 2015a, b; Mordy, 1959; Pinsky et al., 2013; Reutter et al., 2009; Seiki and Nakajima, 2014). We note that throughout this work the word efficient will be used to describe both the rate and the total change of mass attributed to a microphysical process. The processes described above enable the more polluted cloud to condense more water and intensify its growth via increased release of latent heat (Kogan and Martin, 1994; Koren et al., 2014; Saleeby et al., 2015; Sheffield et al., 2015). The smaller droplets are also pushed higher in the atmosphere due to larger droplet mobility (Koren et al., 2014, 2015).

However, the increase in aerosol amount yields suppressing effects as well. An opposite effect should take place in the subsaturated regions of the cloud, where more numerous and smaller droplets increase the evaporation rate and loss of cloud mass (Grant and van den Heever, 2015; Saleeby et al., 2015; Storer and van den Heever, 2013). Henceforth evaporation will be referred to as a process (i.e., change of mass per unit of time) rather than complete evaporation of a water drop. Increased evaporation can promote entrainment mixing, which in turn mixes more subsaturated air into the cloud and further promotes evaporation (Jiang et al., 2006; Small et al., 2009; Xue and Feingold, 2006), effectively initiating a positive feedback between evaporation and mixing with the eventual suppression of cloud growth. This effect may also be accompanied by a suppressing effect of the larger water loading in polluted clouds, which contain more liquid water mass.

The competition between those opposing processes that are driven by enhanced aerosol loading determines the net aerosol effect on cloud properties such as cloud fraction, lifetime, albedo, mass, size, and precipitation amount. However, the sign and magnitude of such effects are non-trivial (Jiang and Feingold, 2006). Previous studies report opposing findings regarding the total aerosol effects on warm clouds (Altaratz et al., 2014). Some studies suggest cloud invigoration by aerosols (bigger and deeper clouds; Dey et al., 2011; Kaufman et al., 2005; Koren et al., 2014; Yuan et al., 2011), while some suggest cloud suppression or no effect at all (Jiang and Feingold, 2006; Li et al., 2011; Savane et al., 2015; Xue et al., 2008). Moreover, other work has shown that the precipitation susceptibility (i.e., quantifies the sensitivity of precipitation to the aerosol increase) has a nonmonotonic behavior that reaches its maximum at intermediate liquid water path (LWP) values (Sorooshian et al., 2009), implying that the resultant aerosol effects are heavily dependent on cloud type and environmental conditions (Khain et al., 2008).

A different approach to aerosol effects suggests that cloud systems can be buffered to microphysical effects (Stevens and Feingold, 2009). Several studies have shown that given enough time for the cloud system to reach steady state, cloud macrophysical parameters (e.g., cloud fraction and rain yield) show similar results for various aerosol concentrations (Carrió and Cotton, 2014; Glassmeier and Lohmann, 2018; Seifert et al., 2015). Based on the idea that clouds can be partitioned to aerosol-limited, updraft-limited, or aerosol- and updraft-sensitive regimes (Reutter et al., 2009), a unified theory for the contradicting results regarding aerosol effects was suggested (Dagan et al., 2015b). Given an aerosol range that covers all three regimes, the competition between opposite processes leads to an optimum value of aerosol concentration regarding various cloud properties like total mass, cloud top, or rain (Dagan et al., 2015b). A cloud that develops under low aerosol concentration is aerosol limited, as it does not have enough collective droplet surface area to consume the available water vapor. On the other side of the trend, a cloud that develops in polluted environment (with more aerosols than the optimum) is influenced significantly by enhanced entrainment and larger water loading, causing suppression of cloud development. The optimal concentration is a function of the thermodynamic conditions (temperature and humidity profiles) and cloud size.

Environments that support larger cloud development will have larger cloud cores that are positively affected by aerosol increase and can be regarded as aerosol limited (i.e., on the ascending branch of the aerosol trend) up to a higher optimal aerosol concentration. Environmental conditions that support small clouds are more strongly affected by cloud suppression processes at the cloud margins (due to higher cloud surface-area-to-volume ratio) and would have a lower optimal aerosol concentration. This can explain why studies biased to smaller clouds (mostly numerical modeling studies) report cloud suppression and studies biased to larger clouds (mostly observational studies) report cloud invigoration. Similar conclusions were reached for the cloud field scale as well (Dagan et al., 2017).

In addition, it was shown that clouds impact differently the environmental thermodynamics according to the aerosol level in the field (Dagan et al., 2016; Seifert and Heus, 2013; Seifert et al., 2015). For example changes in aerosol loading impact the amount of precipitation reaching the surface and subsequently the evaporative cooling below cloud base and the organization patterns (Seifert and Heus, 2013; Seigel, 2014; Xue et al., 2008). Moreover, an increase in aerosol loading may increase evaporation rates around the margins and tops of clouds (Seigel, 2014; Stevens, 2007; Xue and Feingold, 2006), cooling the upper cloudy layer and increasing the convective instability. Therefore aerosol effects on phase changes and precipitation result in vertical redistribution of heat and moisture, which may either stabilize or destabilize the environment in which subsequent clouds grow (Seifert and Heus, 2013).

Irrespective of the definition chosen, the cloud's core and margin are dominated by different processes (Dagan et al., 2015b). These processes often compete with each other, with 
the dominant one changing along the cloud's evolution. For example, at the initial stage of cloud formation, a cloud is more adiabatic and is controlled by the core's processes (condensation), and when it dissipates the margin processes are more dominant (entrainment and evaporation). Aerosols affect each of these processes and thus each stage in the cloud's lifetime. As a continuation of Part 1 (Heiblum et al., 2019) of this work (hereafter PT1), in this part we analyze aerosol effects on the cloud's partition to core and margin throughout the lifetime of a cloud. We report the consequences that these effects have on evolution of a cloud in terms of volume, mass, and lifetime. As opposed to other works that typically focus on a single cloud core definition, here three different definitions are used (see Sect. 2), with emphasis placed on the sensitivity of each core definition to aerosol concentration. Moreover, the combination of single cloud with large-eddy simulations enables us to gain process-level understanding and test the robustness of our findings.

\section{Methods}

The analyses performed here are to the most part identical to those described in PT1 of this work. In this section we shall thus only give a brief review of the methods used. For single cloud simulations we use the Tel Aviv University axisymmetric cloud model (TAU-CM; Reisin et al., 1996), and for cloud field simulations we use the System for Atmospheric Modeling (SAM) model (version 6.10.3; for details see the following web page: http://rossby.msrc.sunysb.edu/ marat/ SAM.html, last access: 10 October 2018; Khairoutdinov and Randall, 2003).

Both models utilize explicit bin-microphysics schemes (Khain et al., 2004; Tzivion et al., 1987), solving nucleation, diffusion (i.e., condensation and evaporation), collisional coalescence, breakup, and sedimentation microphysical processes. The single cloud model is initialized using a Hawaiian thermodynamic profile based on the 91285 PHTO Hilo radiosonde at 00:00 Z on 21 August 2007. The cloud field model is set up based on the BOMEX case study, including an initialization setup (sounding, surface fluxes, and surface roughness) and large-scale forcing setup (Siebesma et al., 2003). More details on the model setups and definitions can be found in PT1.

To study the effects of aerosols on the cloud cores we run each model setup with three different aerosol concentrations: clean $-25 \mathrm{~cm}^{-3}$, intermediate $-250 \mathrm{~cm}^{-3}$, and polluted $2000 \mathrm{~cm}^{-3}$. The model domain is initialized using an oceanic size distribution (Altaratz et al., 2008; Jaenicke, 1988), maintaining a constant mixing ratio with height. The aerosol budget includes removal by nucleation and regeneration upon evaporation, while wet scavenging by precipitation removes aerosols from the domain. Thus, the aerosol concentration may be depleted by $20 \%-40 \%$ (depending on the precipitation amount) during the simulation. More on the treatment of aerosols in the cloud field model can be found in previous work (Heiblum et al., 2016a). As defined in PT1, all pixels with at least $0.01 \mathrm{~g} \mathrm{~kg}^{-1}$ of liquid water are considered cloudy. Cloud cores are defined using three definitions: (1) $\mathrm{RH}_{\text {core }}$ : relative humidity $>100 \%$, (2) $B_{\text {core }}$ : buoyancy $>0$, and (3) $W_{\text {core }}$ : vertical velocity $>0$. Relative humidity $(\mathrm{RH})$ and vertical velocity $(W)$ are standard outputs of the model, while the buoyancy $(B)$ is calculated based on Eq. (1) in PT1, where each cloudy pixel is compared with the mean non-cloudy thermodynamic reference state per height.

In order to reduce the problem's dimensionality and distill signals in a cloud field system governed by high variance, we use the center of gravity vs. mass ( $\mathrm{CvM}$ ) phase space in combination with an automated 3-D cloud tracking algorithm (Heiblum et al., 2016a). The CvM phase space enables a compact view of all clouds in the simulation by projecting only their center-of-gravity (COG) height and mass at each output time step. Using the cloud tracking, it was shown that the lifetime of a cloud can be described by a trajectory on this phase space. Hence, the different locations in the CvM space are associated with different stages in a cloud's lifetime (i.e., growing, precipitating, and dissipating). For an in-depth explanation of the CvM space, the reader is referred to Sect. 2.4 in PT1 (see schematic illustration - Fig. 1, PT1).

\section{Results - single cloud simulations}

\subsection{Sensitivity of different core types to aerosol concentration}

Figure 1 presents time series of single cloud core volume fractions $\left(f_{\mathrm{vol}}\right)$ and cores' properties for three aerosol concentrations (clean, intermediate, and polluted). Also included are time series of instantaneous rain rates $\left(\mathrm{mm} \mathrm{h}^{-1}\right)$ at the domain surface. For all aerosol concentrations and during most of the clouds' lifetimes, the volume fraction of $W_{\text {core }}$ tends to be the largest and the volume fraction of $B_{\text {core }}$ the smallest. Exceptions to this finding are seen either at the initial time step for the polluted cloud or in the later stages of cloud lifetime for the lower-concentration clouds. In addition, we find that $\mathrm{RH}_{\text {core }} \subseteq W_{\text {core }}$ for all stages of cloud lifetime while $B_{\text {core }} \subseteq W_{\text {core }}, \mathrm{RH}_{\text {core }}$ for all stages of the polluted cloud, but this only applies to the growing stages of lowerconcentration clouds before precipitation production. Thus, the main finding from PT1 (i.e., $B_{\text {core }} \subseteq \mathrm{RH}_{\text {core }} \subseteq W_{\text {core }}$ ) generally applies to all aerosol concentrations during the preprecipitation stages of the clouds' lifetimes.

Lower-aerosol-concentration simulations produce more rain and at earlier stages of cloud lifetime due to efficient collision coalescence. The increase in the $B_{\text {core volume fraction }}$ at later stages of cloud lifetime in those simulations (clean and intermediate) coincides with initiation of precipitation production followed by a consequent increase in the $W_{\text {core }}$ volume fraction as well (more so for the intermediate concen- 

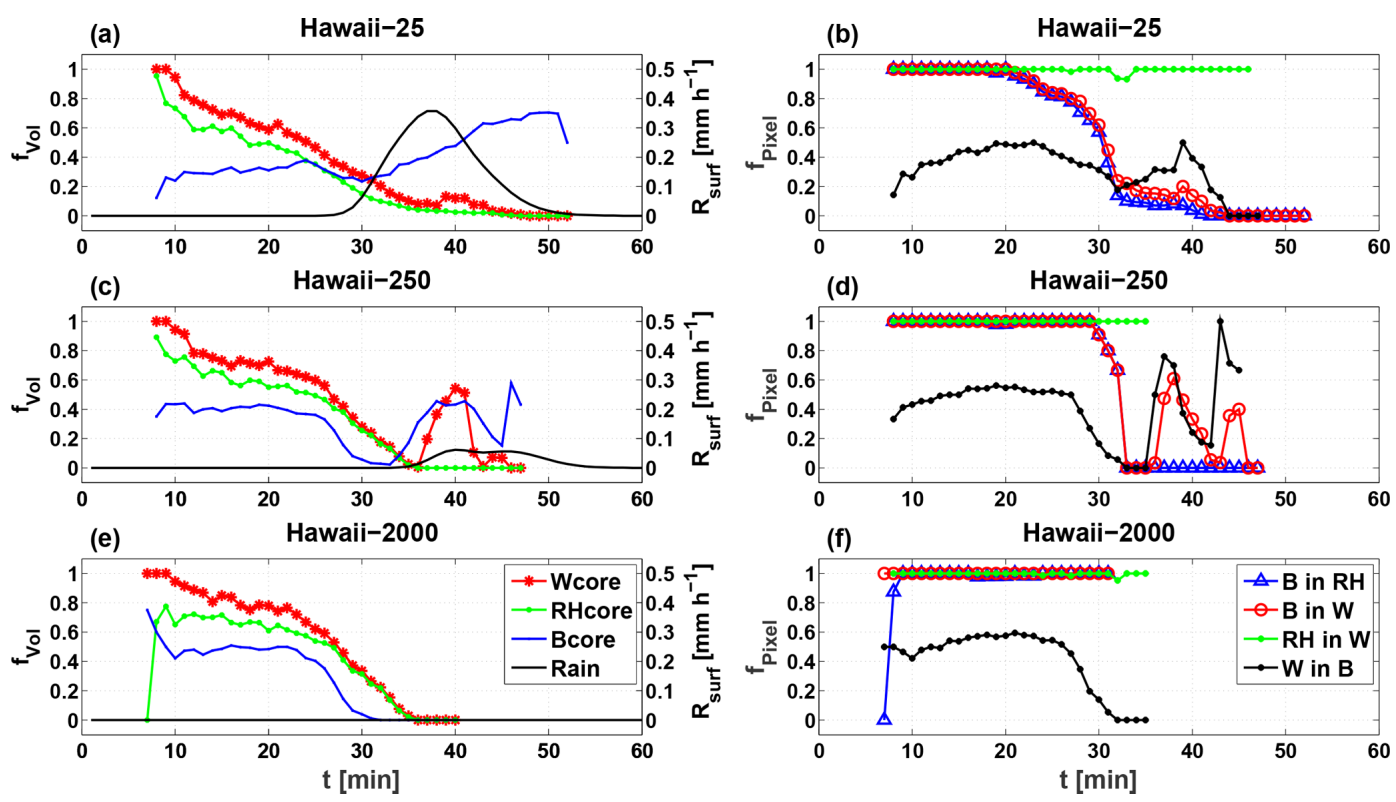

Figure 1. (a, c, e) Time series of core volume fractions $\left(f_{\mathrm{vol}}\right.$ in $\%$; left axis) and surface rain rate $\left(R_{\mathrm{surf}}\right.$ in $\mathrm{mm} \mathrm{h}^{-1}$; right axis) for the clean (a), intermediate (c), and polluted (e) single cloud simulations. (b, d, f) Time series of pixel fractions $\left(f_{\text {pixel }}\right.$ in $\left.\%\right)$ of one core type within another, for the respective simulation types. Core volume and pixel fractions are indicated by different line colors (see legends).

tration). This dissipating $W_{\text {core }}$ is mostly contained within the $B_{\text {core }}$. The possible mechanism behind the increase in prevalence of buoyant parcels during precipitation is explored in Sect. 3.2. The lack of $\mathrm{RH}_{\text {core }}$ pixels at these stages indicates that the $W_{\text {core }}$ is composed of pixels with small vertical velocities, insufficient for supersaturation production. The $\mathrm{RH}_{\text {core }}$ is the only one which is not sensitive to rain and monotonically decreases during all clouds' lifetimes. Another clear aerosol effect seen in Fig. 1 is an increase in cloud lifetime with a decrease in aerosol concentration. This point will be further explored in Sect. 3.3.

\subsection{Mechanisms governing positive buoyancy}

The theoretical arguments in PT1 showed that $B_{\text {core }}$ should be the smallest of the three. This was shown for both the adiabatic cloud column case and also the non-adiabatic case, where entrainment mixing and consequent evaporation have a strong net negative effect on cloud buoyancy. Despite this fact, results show (see Fig. 1 and Fig. 2 in PT1) that pockets of positive buoyancy may form independently of the other cores during dissipation and precipitation stages, even though evaporation is to be expected then. Since positive buoyancy is the result of either higher temperature or vapor content (or both) than the surrounding environment, we choose to analyze these two terms during different stages of the single clouds' lifetimes. The liquid water content (LWC) buoyancy term (not shown here) is always negative and typically increases (in absolute value) with an increase in vertical velocity or total buoyancy.
Figure 2 shows the values of the temperature $\left(B_{\mathrm{T}}\right)$ and humidity $\left(B_{\mathrm{Qv}}\right)$ buoyancy terms in pixel buoyancy vs. pixel vertical velocity phase space. The scatterplots include all cloudy pixels during all time steps for the three different aerosol concentration simulations. The distribution of points for the polluted simulation shows a positive linear dependence of buoyancy on vertical velocity. Negative vertical velocity is associated with negative buoyancy, and positive vertical velocity shows a transition from negative to positive buoyancy with an increase in magnitude. For this case both $B_{\mathrm{T}}$ and $B_{\mathrm{Qv}}$ increase with an increase in vertical velocity, as is generally expected in convective clouds. The sign of pixel buoyancy is mostly dependent on $B_{\mathrm{T}}$, since all pixels have positive $B_{\mathrm{Qv}}$ and a negative water loading term. This behavior is also seen for lower aerosol concentrations, where the sign of buoyancy is for the most part determined by $B_{\mathrm{T}}$. Hereafter, we refer to positive buoyancy (both $B_{\mathrm{T}}$ and $B_{\mathrm{Qv}}$ ) production within updrafts as updraft buoyancy.

The clean and intermediate simulations show a similar dependence of buoyancy on vertical velocity; however, it is apparent that these simulations also include an outlier scatter region of pixels with positive buoyancy and weak negative vertical velocity which is absent in the polluted simulation (see white arrows; Fig. 2). Consistent with the rest of the cloudy pixels, these outlier pixels have positive $B_{\mathrm{T}}$ but differ in that they show neutral $B_{\mathrm{Qv}}$. It can also be seen that these pixels are only attributed to the stages after surface precipitation has commenced (indicated by black dots in markers). Precipitation is indicative of both downdraft motion and abundance of large drop sizes. 

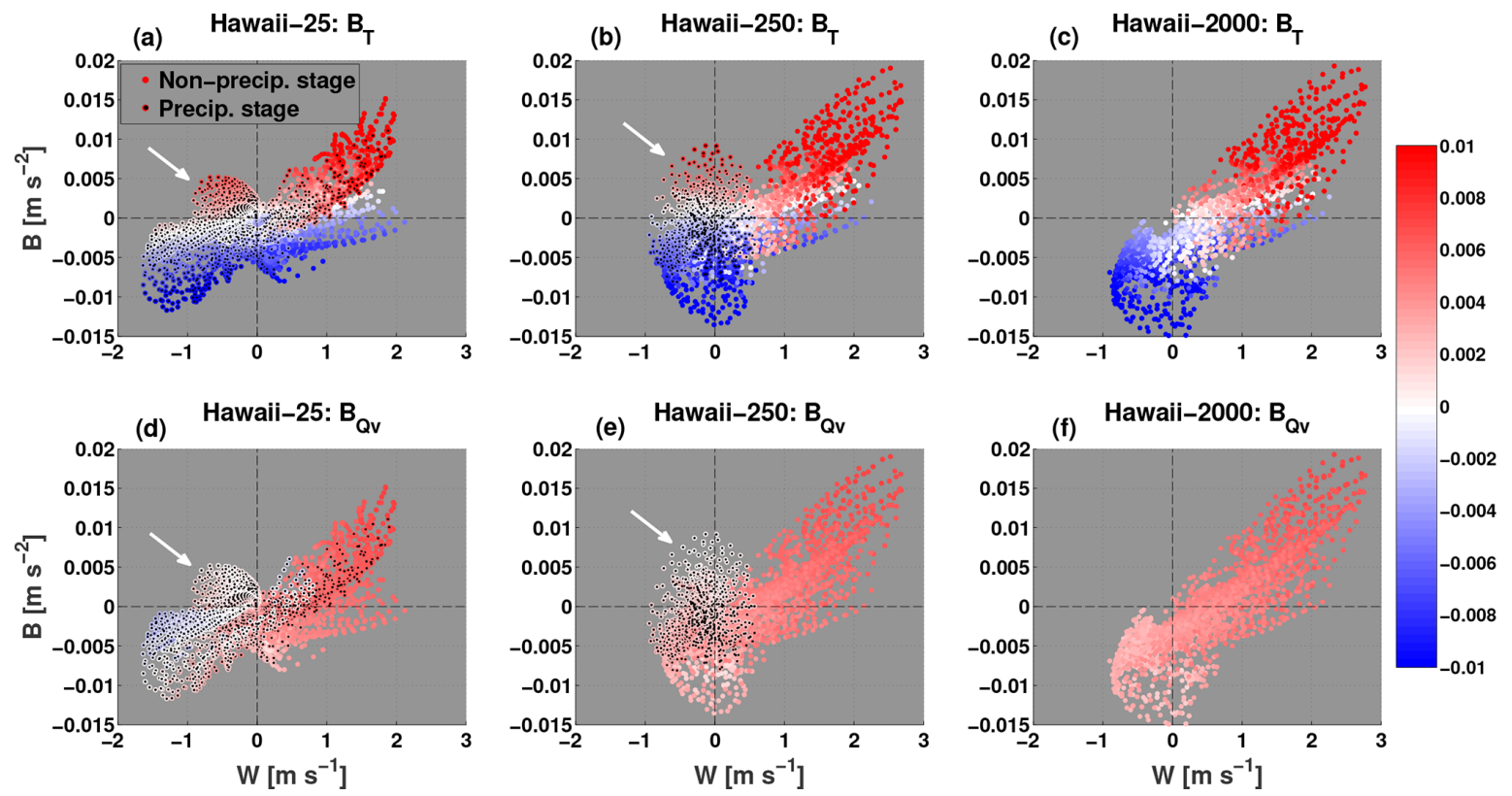

Figure 2. Scatterplots of pixel total buoyancy $\left(\mathrm{m} \mathrm{s}^{-2}\right)$ vs. pixel vertical velocity $\left(\mathrm{m} \mathrm{s}^{-1}\right)$ for the clean (a, d), intermediate (b, e), and polluted (c, f) simulations. Data include all cloudy pixels during all time steps. Colors represent magnitude of buoyancy temperature term $\left(B_{\mathrm{T}} ; \mathbf{a}, \mathbf{b}, \mathbf{c}\right)$ and humidity term $\left(B_{\mathrm{Qv}} ; \mathbf{d}, \mathbf{e}, \mathbf{f}\right)$, where red (blue) shades indicate positive (negative) values. Markers with superimposed black dots represent temporal stages with non-zero surface precipitation. White arrows indicate outlier scatter of pixels with positive buoyancy and negative vertical velocity.

Although not usually the focus of studies, the existence of positively buoyant downdrafts in convective clouds has been reported in both observations (Igau et al., 1999; Wei et al., 1998) and simulations (Xu and Randall, 2001; Zhao and Austin, 2005a, b). A possible explanation for this can be deduced from previous theoretical studies predicting mixinginduced downdrafts in cumulus clouds (Betts and Silva Dias, 1979; Betts, 1982). It was shown that in some cases cloudenvironment mixtures are negatively buoyant (while still containing liquid water), and the consequent downdrafts can sometimes descend only partway down to the cloud base before reaching neutral buoyancy. Similar to convective overshooting, parcels with negative vertical momentum may then undershoot the downdraft equilibrium level and turn positively buoyant while the downdraft weakens. One can therefore expect the magnitude of positive buoyancy within the downdraft to reach a maximum when the velocity approaches zero. Hereafter we refer to positive buoyancy production within downdrafts as downdraft buoyancy.

Downdraft buoyancy production occurs frequently in cumulus fields because the negatively buoyant downdrafts follow a warming lapse rate which is more unstable than the environmental one, which is typically between the dry adiabat and moist adiabat (as is the case for the Hawaiian and BOMEX profiles simulated in this work). On one extreme, a descending parcel is least buoyant (i.e., coolest) when evaporation (after mixing) keeps it just barely saturated (Paluch and Breed, 1984, also PT1) so that the lapse rate of descent tends to be moist adiabatic and may remain negatively buoyant. On the other extreme, if little to no evaporation of liquid water occurs, the descent will follow the dry adiabat and switch to neutral (and then positive) buoyancy rapidly. Thus, the ability of a negatively buoyant cloudy downdraft to sustain itself depends on continuous inflow of liquid water (by mixing) and its consequent evaporation (Knupp and Cotton, 1985).

Indeed, the results in Fig. 2 match the hypothesis explained above, where positively buoyant downdrafts are warmer than the environment and tend to show larger buoyancy values for weaker downdraft velocities (especially for the intermediate case). Further analysis also shows that the more unsaturated the downdrafts (indicated also by low $B_{\mathrm{Qv}}$ ), the larger the positive buoyancy. Moreover, the occurrence during precipitating stages and for lower aerosol concentrations indicates that slow evaporation due to larger drop sizes is crucial for downdraft buoyancy production, enabling a near-dry adiabatic lapse rate during descent.

\subsection{The dependency of cloud characteristics on core and margin's processes}

Here we evaluate how aerosol effects within the core and margin (using the three core definitions) affect the cloud characteristics, focusing on two main parameters: size (or volume) and mass. In Fig. 3 we follow the evolution of cloud, core, and margin mass and volume for different aerosol con- 
centrations, using only the $\mathrm{RH}_{\text {core }}$ definition. We choose the $\mathrm{RH}_{\text {core }}$, since it is the most stable out the core types, generally decreasing monotonically (see Fig. 1). A non-monotonic dependency of total cloud mass on aerosol concentration is seen, showing a maximum for the intermediate concentration. This type of dependency has been previously reported for warm cumulus clouds (Dagan et al., 2015b; Savane et al., 2015).

One can generally expect an increase in diffusion and decrease in collision-coalescence processes efficiency with an increase in aerosol concentration (Hudson and Yum, 2001; Jiang et al., 2009; L'Ecuyer et al., 2009; Pinsky et al., 2013), affecting both condensation and evaporation processes. The intermediate concentration shows the highest total mass as a result of being an optimal case, with higher condensation efficiency than the clean case and lower evaporation efficiency than the polluted case. It is convenient to represent the condensation and evaporation efficiencies by the $\mathrm{RH}_{\text {core }}$ and $\mathrm{RH}_{\text {margin }}$ mass, respectively. The intermediate cloud has almost identical core mass as the polluted cloud but retains higher mass in its margin as well. The clean cloud shows the lowest core mass but manages to accumulate the largest mass in its margin that dissipates slowly in subsaturated conditions. By comparing the total cloud mass evolution with the core and margin mass evolutions, it becomes clear that the total mass is primarily dependent on the cloud core. Another way to see this is by plotting the core mass fraction (Fig. 3g), which shows that clouds are core dominated (core fraction $>0.5$ ) with respect to mass for most of their lifetimes and for all aerosol concentrations.

With respect to cloud total volume, the lower the concentration, the larger the total cloud volume. We note that the cloud volume here excludes regions of precipitation below the initial cloud base height. By separating to core and margin regions, one can see that the total cloud volume is primarily dependent on the volume of the margin, which increases significantly with decreasing concentration. This is especially true during the dissipating stages of cloud lifetime, when the cloud is margin dominated. Although increasing the aerosol concentration does initially yield an increase in core volume (as was seen for the mass), the extents of the core size are typically smaller than those of the margin. There are large differences in the relative core volume percentage for the different clouds. The clean (polluted) cloud is margin (core) dominated with respect to volume for most of its lifetime. Excluding time of formation, the clean cloud shows the lowest core volume fractions but manages to maintain its core for the longest time span.

These results with respect to cloud volume can be attributed to the smaller drop sizes and higher diffusion efficiencies with an increase in aerosol concentration. Additionally, lower collision-coalescence efficiencies also maintain a narrow droplet spectrum of small droplets in the polluted cloud. During the growing stage a higher aerosol concentration may permit the cloud to condense more water, release more latent heat, and promote cloud growth. This explains the larger core volume sizes. However, after the cloud exhausts its convective potential (i.e., the growth of the convective core terminates and reaches its peak in mass), its main method of expansion is by mixing with the environment (i.e., detrainment and dilution). We note that precipitation can also be considered a method of expansion; however our choice to focus on volume above initial cloud base excludes this effect. Detrainment and mixing with the environment result in subsaturation conditions and evaporation of LWC. A clear indication for dilution is seen in Fig. 3, where between 30 and 35 min of simulation time, both the clean and polluted clouds lose total mass but only the clean cloud increases in total volume. The polluted cloud is composed of small drops, evaporates its margin regions efficiently, and is thus limited in horizontal growth by detrainment. The clean cloud is composed of larger drops, less efficient in evaporating its margins, and hence can grow by dilution of its LWC upon a larger volume. This large margin "shields" the core during dissipation stages and enables it to the live for a longer time.

The mechanism behind the results in Fig. 3 is demonstrated in Fig. 4, where horizontal cross-sections of mean (taken in the vertical dimension) cloud RH are shown for different stages during the clouds' lifetimes. For the polluted cloud, supersaturated or subsaturated conditions are rare. The RH throughout the cloud is near $100 \%$ (almost always between $99.8 \%$ and $100.2 \%$ ) except for a few pixels at its far edges which are a bit below $99 \%$. The polluted cloud resembles what one would expect to see using a moist adiabatic approximation (i.e., saturation adjustment), where all excess water vapor above saturation is converted to liquid water, mimicking infinitely efficient condensation (and evaporation).

The clean cloud shows opposite behavior, with extremes of large supersaturation during cloud growth (initial stages) and large subsaturation during cloud dissipation (final stages). The large supersaturation can be explained by slow diffusional growth, but the large subsaturation also takes into consideration the larger drop sizes, which take more time to evaporate. This enables the clean cloud to expand to larger horizontal extents (by dilution and mixing with the environment without fully evaporating) and live for longer times. The intermediate aerosol concentration shows a midway scenario, where the supersaturation is consumed more efficiently than the clean case and at the same time much larger values of subsaturation may exist than those seen for the polluted case.

\section{Results - cloud field simulations}

In the following section we expand our analyses of aerosol effects on cloud core and margin from the single cloud scale to the cloud field scale. A cloud field can be considered to be composed of many individual clouds and thus can serve 

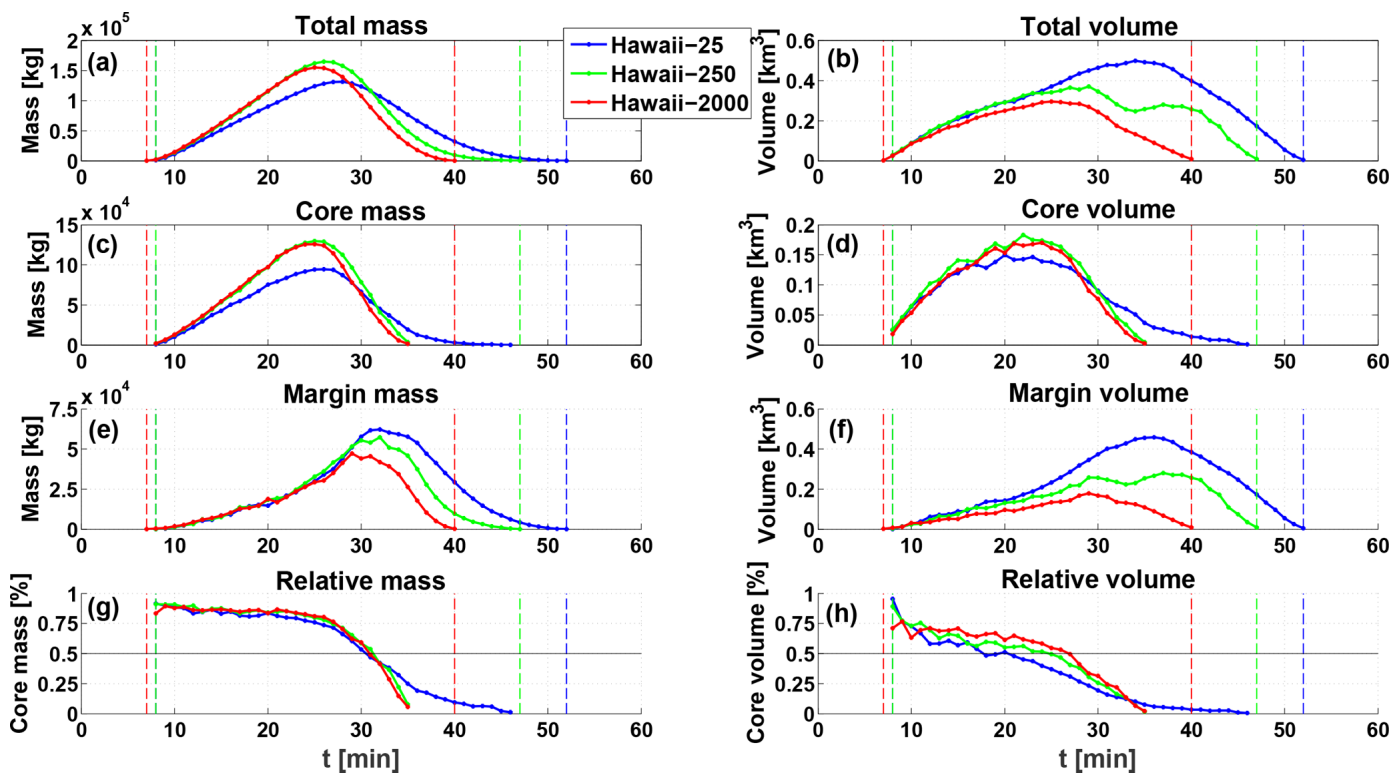

Figure 3. Time series of cloud mass $(\mathrm{kg} ; \mathbf{a}, \mathbf{c}, \mathbf{e}, \mathbf{g})$ and cloud volume $\left(\mathrm{km}^{3} ; \mathbf{b}, \mathbf{d}, \mathbf{f}, \mathbf{h}\right)$ for the different aerosol concentrations simulations (see legend). The total $(\mathbf{a}, \mathbf{b})$, core $(\mathbf{c}, \mathbf{d})$, margin $(\mathbf{e}, \mathbf{f})$, and relative fraction $(\mathbf{g}, \mathbf{h})$ values are shown for each parameter, as indicated by panel titles. The core here is defined according to $\mathrm{RH}>100 \%$ definition.
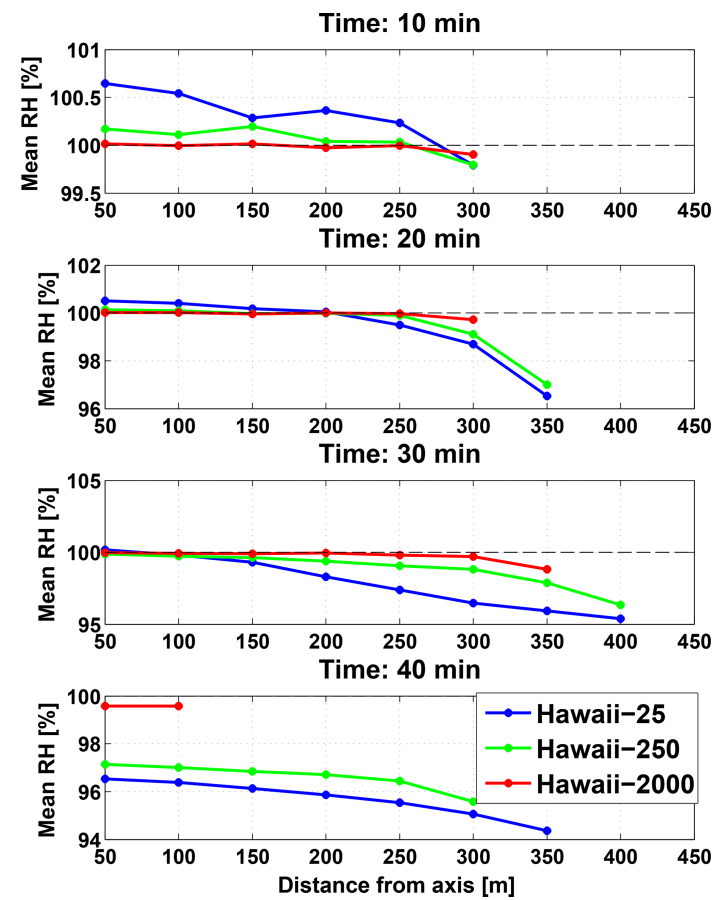

Figure 4. Four snapshots of horizontal cross-sections of RH (\%; see panel titles for times). Panels include the results of different aerosol concentrations (see legend). Cross-sections are obtained by taking the mean $\mathrm{RH}$ of all vertical levels for each horizontal distance from the cloud center axis. to test the robustness of the aerosol effects seen for a single cloud. Moreover, cloud fields include the added complexity of interactions between clouds and the clouds' effects on their thermodynamic environment.

\subsection{Sensitivity of different core types to aerosol concentration}

Here CvM space representations (see Sect. 2) are used to observe the core volume fractions of all clouds in BOMEX cloud field simulations. The rows in Fig. 5 represent different aerosol concentrations, while the columns represent different core type definitions. Different aerosol concentrations produce a vastly different scatter of clouds in the CvM space, as was previously discussed in depth (Heiblum et al., 2016b). The clean simulation $\left(25 \mathrm{~cm}^{-3}\right)$ shows two disconnected regions of cloud scatter: one which is adjacent to the adiabatic approximation and one of mainly small mass and highCOG clouds. The former region includes both clouds during their growth stages (smaller masses, LWP $<10 \mathrm{~g} \mathrm{~m}^{-2}$ ) and large precipitating entities (larger masses, LWP $>10 \mathrm{~g} \mathrm{~m}^{-2}$ ) which form due to merging processes (Heiblum et al., 2016b). The latter region (small mass and high COG) includes clouds at their dissipating stage, which form by the shedding mechanism off the large cloud entities. We note also the existence of small-mass elements well below the adiabat, representing precipitation cloud segments which shed off large precipitating clouds.

The polluted simulation $\left(2000 \mathrm{~cm}^{-3}\right)$ shows a much more homogeneous scatter of clouds. The lower part of the scatter (closest to the adiabat) represents the cloud growing branch, 

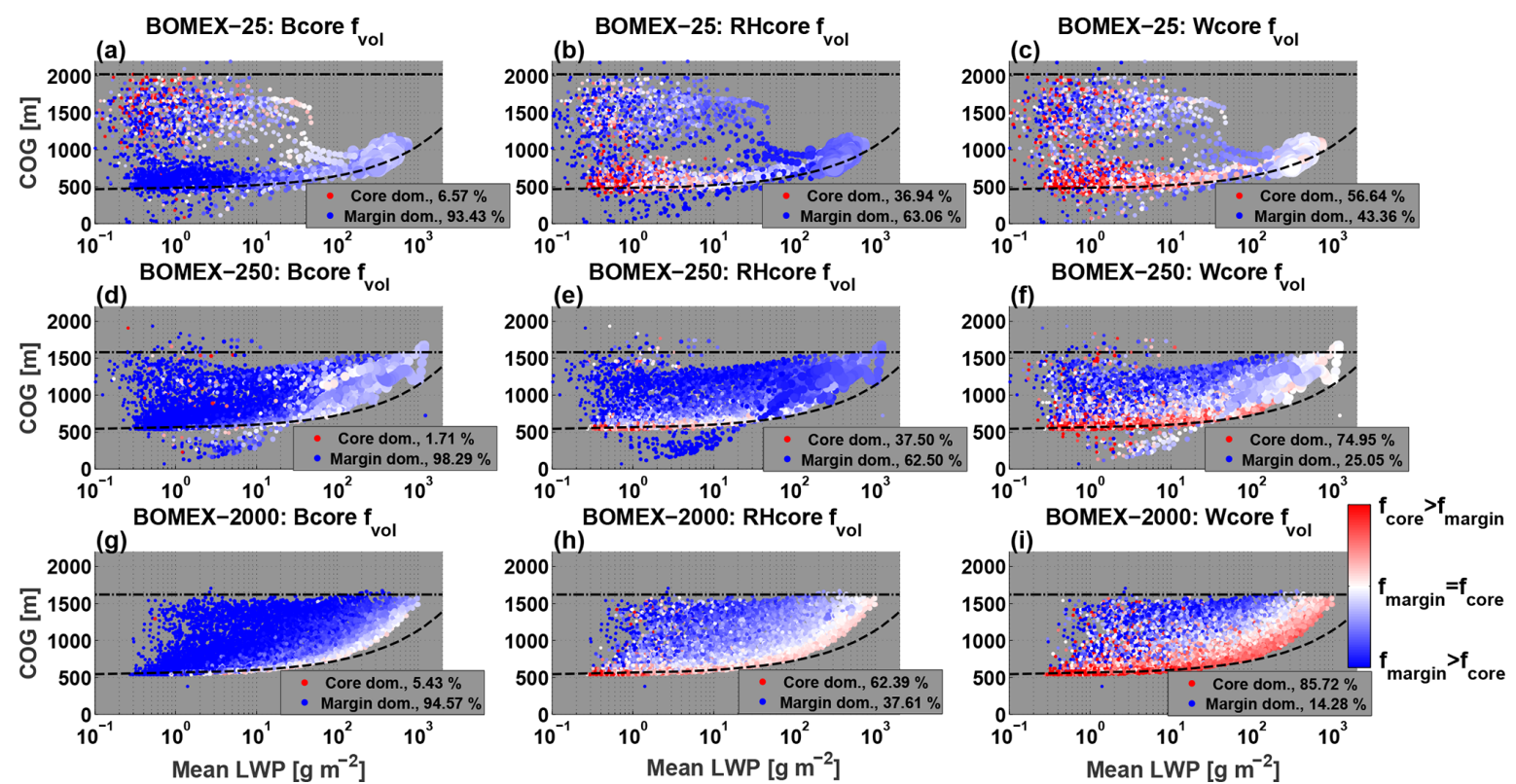

Figure 5. CvM phase-space diagrams of $B_{\text {core }}(\mathbf{a}, \mathbf{d}, \mathbf{g}), \mathrm{RH}_{\text {core }}(\mathbf{b}, \mathbf{e}, \mathbf{h})$, and $W_{\text {core }}(\mathbf{c}, \mathbf{f}, \mathbf{i})$ volume fractions $\left(f_{\mathrm{vol}}\right)$ for all clouds between 3 and $8 \mathrm{~h}$ in the BOMEX simulations. The rows correspond to the clean $(\mathbf{a}, \mathbf{b}, \mathbf{c})$, intermediate $(\mathbf{d}, \mathbf{e}, \mathbf{f})$, and polluted $(\mathbf{g}, \mathbf{h}, \mathbf{i})$ aerosol cases. The red (blue) colors indicate a core $f_{\mathrm{vol}}$ above (below) 0.5 . The size of each point in the scatter is proportional to the cloud mean area, where the smallest (largest) point corresponds to an area of $0.01 \mathrm{~km}^{2}\left(11.4 \mathrm{~km}^{2}\right)$. The percentage of clouds that are core dominated $\left(\mathrm{f}_{\mathrm{vol}}>0.5\right)$ is included in panel legends. For an in-depth description of CvM space characteristics, the reader is referred to Sect. 2.4 in PT1.

while the rest of the scatter represents dissipating clouds, either by the gradual process of rising cloud base or by an immediate process of shedding off larger cloud entity (see Fig. 1, PT1). Precipitating cloud segments below the adiabat are absent from this simulation. The intermediate simulation $\left(250 \mathrm{~cm}^{-3}\right)$ shows a scatter which generally resembles the polluted case. However, the existence of relatively disconnected (from the main cloud scatter) small-mass cloud segments below the adiabat and near the inversion base height resembles the clean simulation as well. It should be noted that horizontal dashed lines in Fig. 5 represent the inversion base height after $5 \mathrm{~h}$ of simulation (approximately middle of simulation), where an increase in the inversion base height is seen with a decrease in aerosol concentration. This is due to increased net warming in the upper cloudy layer (i.e., release of latent heat during condensation with reduced local evaporation) with an increase in precipitation (Dagan et al., 2016; Heiblum et al., 2016b), which raises the inversion base.

The results in Fig. 5 show a consistent behavior of the core volume fractions for all aerosol concentrations, where the $W_{\text {core }}$ type shows the largest fractions and the $B_{\text {core }}$ type shows the smallest fractions. The $W_{\text {core }}$ and $\mathrm{RH}_{\text {core }}$ generally show a decrease in core fractions along the growing branch, while the $B_{\text {core }}$ fraction initially increases with cloud growth and then decreases for the large-mass growing clouds. The percentages in the panel legends (Fig. 5) indicate the fraction of clouds (out of the scatter) which are core dominated with respect to volume $\left(f_{\mathrm{vol}}>0.5\right)$. For all concentrations, less than $7 \%$ of clouds are $B_{\text {core }}$ dominated, while more than $55 \%$ are $W_{\text {core }}$ dominated (with $\mathrm{RH}_{\text {core }}$ percentages somewhere in between). The $B_{\text {core }}$ typically occupies a small portion of a typical cloud volume, while the $W_{\text {core }}$ typically occupies most of the cloud. The mean cloud area (proportional to scatter point size) shows an increase with the increase in mean cloud LWP.

These results are consistent with PT1 and the single cloud simulations in Sect. 3.1. Nevertheless, some significant aerosol effects on the partition to core types can be seen. Focusing on the growing branch first (i.e., clouds located near the adiabat), we note the following:

1. For the $\mathrm{RH}_{\text {core }}$ type, the core volume fractions of clouds after formation (i.e., with small mass) increase with decreasing aerosol concentration. This effect was also seen for the single cloud simulations and can be explained by the reduced efficiency of supersaturation consumption for fewer aerosols.

2 . The $B_{\text {core }}$ volume fraction increases at smaller mass values (or earlier in cloud's lifetime) and to higher values for increasing aerosol concentration. This effect is complementary to the previous one, since efficient consumption of supersaturation should result in more latent heat release and positive buoyancy.

3. The core volume fractions of the largest mass clouds increase with increasing aerosol concentration for all core types. 

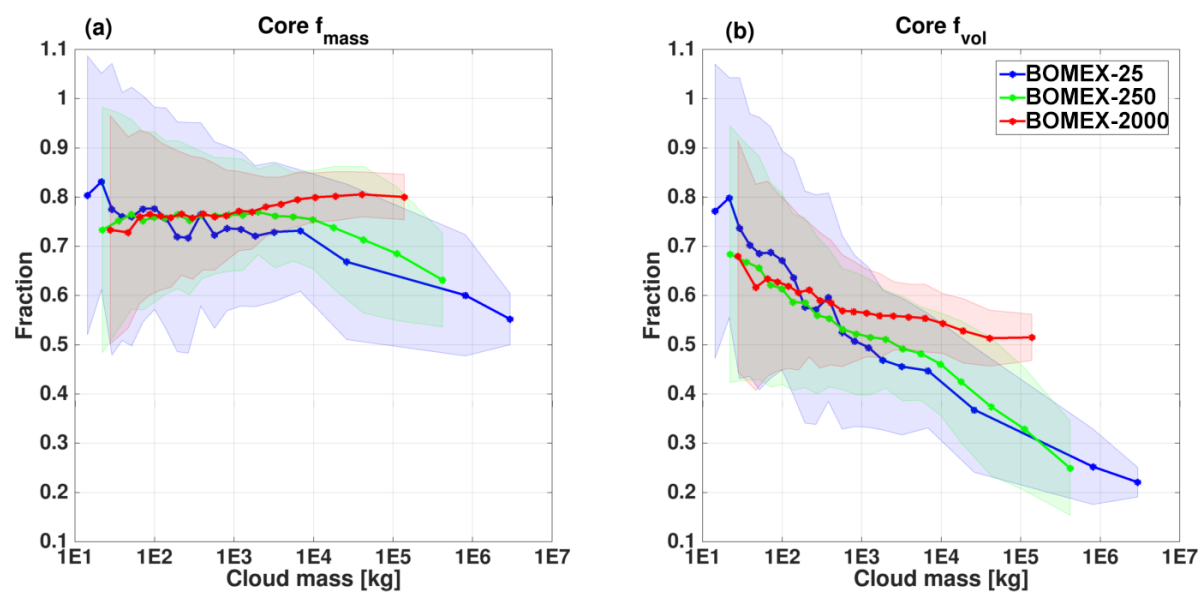

Figure 6. Average core mass fraction (a) and volume fraction (b) values for different aerosol concentrations, as indicated in the legend. The average only includes growing branch clouds from within the CvM space (i.e., clouds located in proximity to the adiabat). The core here is defined according to $\mathrm{RH}>100 \%$ definition.

4. The mean area of large-mass clouds increases significantly with a decrease in aerosol concentration.

We also note a general increase in the fraction of clouds that are $W_{\text {core }}$ or $\mathrm{RH}_{\text {core }}$ dominated with an increase in aerosol concentration, meaning adding aerosols shift a cloud from being mostly margin to being mostly core. The $B_{\text {core }}$ is an exception, since the clean case shows the highest fraction of $B_{\text {core-dominated clouds, and both the clean and polluted }}$ cases are more $B_{\text {core }}$ dominated than the intermediate case. This can be explained by the different mechanisms of buoyancy production (see Sects. 3.2 and 4.2), where the polluted case is positively influenced by updraft buoyancy production and a larger core volume fraction, while the frequently precipitating clean case is positively influenced by downdraft buoyancy production. For the dissipating branch clouds, a highly variable pattern of core volume fractions can be seen, especially for the small-mass clouds. For all aerosol concentrations, these small cloud fragments can be either core dominated, margin dominated, or equally partitioned. One can assume that these differences can be related to the different mechanisms by which cloud fragments form, either by gradual dissipation of a large cloud or by instantaneous shedding of a large cloud. As for aerosol effects on the dissipating clouds, we see the following:

1. Higher $\mathrm{RH}_{\text {core- }}$ and $W_{\text {core-volume fractions for gradu- }}$ ally dissipating clouds (by rising cloud base) with an increase in aerosol concentration. This is manifested by a slower transition from red to blue colors in Fig. 5. It can be explained by the fact that more aerosols increase the convective intensity and extend the core size, while efficiently losing the margins, yielding a higher-corevolume fraction out of the total cloud.

2. The likelihood of finding dissipating cloud fragments with a $B_{\text {core }}$ increases with a decrease in aerosol con- centration. For the polluted case most of the dissipating clouds lack a $B_{\text {core }}$. This effect was seen in Fig. 1 and explained in Sect. 3.2, showing that downdrafts promote heating and positive buoyancy in low aerosol concentration cases where evaporation efficiency (and hence cooling) is limited. This effect is checked for the cloud field scale in Sect. 4.2.

As opposed to the single cloud simulations (Sect. 3) where cloud lifetime can be easily defined, in cloud field simulations (especially the cleaner cases) many clouds do not live as individual clouds from formation to dissipation but rather split and merge with other clouds continuously (Heiblum et al., 2016b). Thus, in order to evaluate the lifetime evolution of cores in cloud fields, we focus on the growing branch and use cloud mass $(\mathrm{kg})$ as a proxy for the cloud lifetime during its initial and mature stages. We assume that in the vicinity of the growing branch a larger mass corresponds to a later stage in its lifetime.

In Fig. 6 the core mass and volume fractions $\left(f_{\text {mass }}\right.$ and $f_{\mathrm{vol}}$, using the RH definition) of all growing branch clouds are sorted by mass for the three aerosol concentrations. We note that the higher cloud masses reached by loweraerosol-concentration simulation can be explained by cloud field organization effects due to precipitation (i.e., increased merging of clouds) rather than increased cloud condensation (Heiblum et al., 2016b; Seigel, 2014). The clean case starts off with the highest core fractions (both mass and volume), which decrease steadily with an increase in mass (or increase in lifetime). For all concentrations, most of the cloud mass is concentrated in the core region. The polluted case shows a slight increase in core mass fractions with increase in mass, while the other two cases show decreases in core mass fractions.

The core volume fractions show lower values than the mass fractions. The clean clouds are margin dominated for 

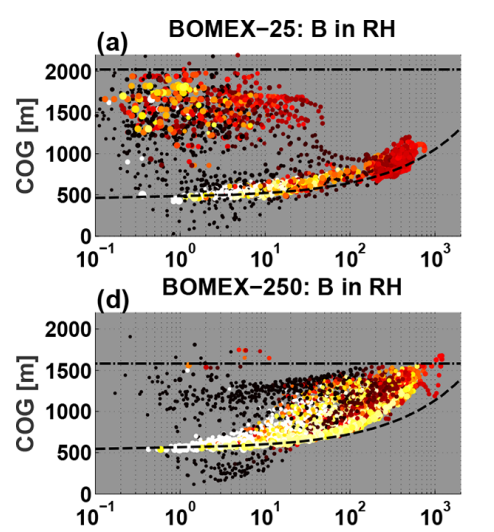

(g)
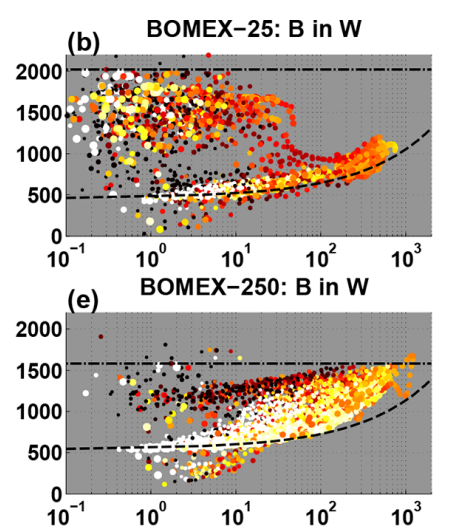

(h)

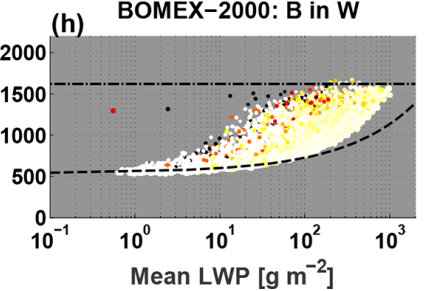

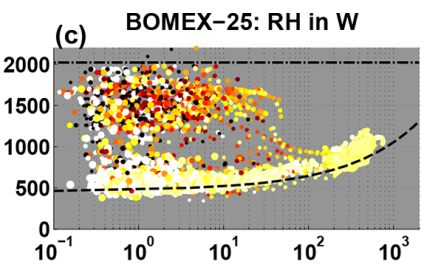

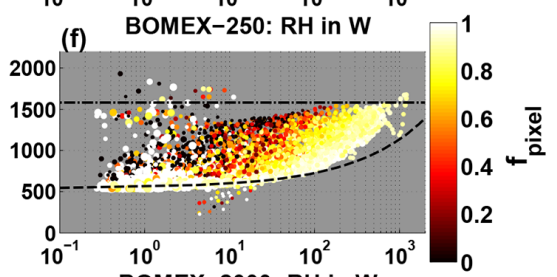

(i)

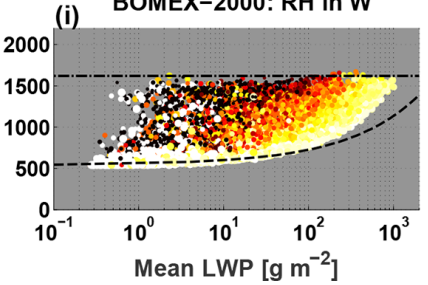

Figure 7. CvM space diagrams showing the pixel fractions $\left(f_{\text {pixel }}\right)$ of $B_{\text {core }}$ within $\mathrm{RH}_{\text {core }}(\mathbf{a}, \mathbf{d}, \mathbf{g}), \mathrm{B}_{\text {core }}$ within $W_{\text {core }}(\mathbf{b}, \mathbf{e}, \mathbf{h})$, and $\mathrm{RH}$ core within $W_{\text {core }}(\mathbf{c}, \mathbf{f}, \mathbf{i})$ for the clean (top row, $\mathbf{a}, \mathbf{b}, \mathbf{c}$ ), intermediate (middle row, $\mathbf{d}, \mathbf{e}, \mathbf{f}$ ), and polluted (bottom row, $\mathbf{g}, \mathbf{h}, \mathbf{i}$ ) simulations. Bright colors indicate high-pixel fractions (large overlap between two core types), while dark colors indicate low-pixel fractions (little overlap between two core types). The differences in the scatter density and location for different panels are due to the fact that only clouds which contain a core fraction above zero (for the core in question) are considered.

most masses, and the polluted clouds are core dominated for all masses. The intermediate case is generally confined to values between the other two cases. Figure 6 can be considered comparable with the lower panels in Fig. $3 \mathrm{~g}$ and $\mathrm{h}$, but excluding the dissipating part of those time series. The similar findings in both figures indicate the robustness of the aerosol effects on core properties in clouds.

Following the analyses of Sect. 3.1, we next test how aerosol concentration affects the subset properties of one core type within another for all clouds in a field (Fig. 7). We focus only on the typically smaller-sized cores $\left(B_{\text {core }}\right.$, $\left.\mathrm{RH}_{\text {core }}\right)$ within larger-sized cores. Out of the three permutations, the $\mathrm{RH}_{\text {core }}$ inside $W_{\text {core }}$ shows the lowest sensitivity to aerosol. All three growing branches (for the different aerosol concentrations) consistently show that the $\mathrm{RH}_{\text {core }}$ is a subset of $W_{\text {core }}$ (i.e., $\mathrm{RH}_{\text {core }} \subseteq W_{\text {core }}$ ), while the dissipation branches show much lower overlap fraction between the two cores.

For the dissipating clouds in general, the lower the mass and the higher the COG, the smaller the overlap. The dissipating branches do include a scatter of small cloud for which $\mathrm{RH}_{\text {core }} \subseteq W_{\text {core }}$, comprised of small cloud segments which shed off the main core regions of larger clouds. These findings slightly differ from those of the single cloud simulations that show $\mathrm{RH}_{\text {core }} \subseteq W_{\text {core }}$ for their entire lifetimes, while for cloud fields this property breaks down during dissipation. This difference highlights the importance of cloud interactions (i.e., splitting and merging) and cloud field air flow pat- terns (i.e., organized advection, updrafts, and downdrafts) in determining the relationships between core types, enabling supersaturation and downdrafts to coincide in small dissipating clouds.

The other two permutations (i.e., $B_{\text {core }}$ inside $\mathrm{RH}_{\text {core }}$, $W_{\text {core }}$ ) show significant changes due to aerosol. For the polluted case, $B_{\text {core }} \subseteq W_{\text {core }}$ for nearly all clouds, including clouds at initial stages of dissipation. Similar results are seen for $B_{\text {core }}$ inside $\mathrm{RH}_{\text {core }}$, but with slightly lower pixel fractions. The polluted case thus illustrates the case of buoyancy production due to convective updraft. For the lower aerosol concentrations, two main aerosol effects are seen:

1. The lower the concentration, the lower the chance that $B_{\text {core }}$ is a proper subset of the other cores for large growing branch clouds.

2. The lower the concentration, the more prevalent the independent dissipating branch $B_{\text {core }}$ that has little to no overlap with the other cores.

For the case of $B_{\text {core }}$ within $\mathrm{RH}_{\text {core }}$, the lower concentrations show an almost-binary scenario where either $B_{\text {core }} \subseteq \mathrm{RH}_{\text {core }}$ or $B_{\text {core }} \notin \mathrm{RH}_{\text {core }}$. These results bear similarity to the single cloud simulations, where a quick transition (in time) from $B_{\text {core }} \subseteq \mathrm{RH}_{\text {core }}$ to $B_{\text {core }} \notin \mathrm{RH}_{\text {core }}$ was seen. These results imply the existence of two different buoyancy production processes (more in Sect. 4.2), one associated with supersaturation and the other with subsaturation. In contrary, pixels 
fractions of $B_{\text {core }}$ inside $W_{\text {core }}$ span the entire range of values (i.e., partial overlaps between the core types), as seen for both single clouds and cloud fields during dissipation. This is to be expected due to a more direct physical link and feedbacks between the $B_{\text {core }}$ and $W_{\text {core }}$.

\subsection{Analysis of cloud field buoyancy}

In Sect. 3.2 it was seen that for single clouds, positive buoyancy results from two main mechanisms: (i) convective updrafts - where updrafts promote supersaturation and latent heat release, and thus always positive $B_{\mathrm{Qv}}$ and frequently positive $B_{\mathrm{T}}$ - and (ii) dissipative downdrafts - where subsaturated cloudy downdrafts promote a positive $B_{\mathrm{T}}$ and neutral $B_{\mathrm{Qv}}$. The latter case is dependent on low evaporation efficiency and hence seen mostly for precipitating stages of low aerosol concentration simulations. In Fig. 8 we perform a similar test for the cloud field scale. Instead of analyzing pixel by pixel, we check whether each buoyancy core within a cloud is $B_{\mathrm{T}}$ or $B_{\mathrm{Qv}}$ dominated. To quantify this we use a normalized buoyancy dominance parameter $\frac{\Sigma \text { pixel }_{B_{\mathrm{T}}>0}-\Sigma \text { pixel }_{B_{\mathrm{Qv}}>0}}{\Sigma \text { pixel }_{B>0}}$, where a core comprised of only $B_{\mathrm{T}}>0\left(B_{\mathrm{Qv}}>0\right)$ pixels yields $1(-1)$. Hence, we expect negative (positive) values to indicate dominance of updraft buoyancy (downdrafts buoyancy).

Analysis of the buoyancy components in the CvM space (Fig. 8c, f, and i) shows that the large majority of clouds are $B_{\mathrm{Qv}}$ dominated. For all concentrations, clouds initiate with all pixels showing $B_{\mathrm{Qv}}>0$. As clouds develop along the growing branch the $B_{\text {core }}$ becomes more abundant with $B_{\mathrm{T}}>0$ pixels. This is expected with increasing release of latent heat during cloud growth. During dissipation $B_{\mathrm{Qv}}$ again becomes the dominant component for the majority of clouds. The polluted simulation shows an extreme case where all buoyancy cores in the simulation are $B_{\mathrm{Qv}}$ dominated, while for the lower concentrations a portion of the dissipating and precipitating clouds are $B_{\mathrm{T}}$ dominated.

Thus, we hypothesize that the polluted simulation only permits buoyancy cores of the updraft type which intersect with the other core types (i.e., $B_{\text {core }} \in \mathrm{RH}_{\text {core }}, W_{\text {core }}$ ), while the lower concentrations also permit buoyancy cores of the downdraft type which do not intersect with the other core types (i.e., $B_{\text {core }} \notin \mathrm{RH}_{\text {core }}, W_{\text {core }}$ ). We test this by observing the relation of cloud maximum absolute vertical velocity (Fig. 8a, d, and g) and mean drop size (Fig. 8b, e, and h) with the relative dominance of the buoyancy terms. Absolute vertical velocity is chosen to represent both updrafts and downdrafts. The data are further separated into independent ( $B_{\text {core }} \notin \mathrm{RH}_{\text {core }}, W_{\text {core }}$ ) and dependent ( $B_{\text {core }} \in \mathrm{RH}_{\text {core }}$, $\left.W_{\text {core }}\right)$ buoyancy subsets of the data by that separating to buoyant cores within updrafts and downdrafts. Clear aerosol effects are seen on cloud mean drop size and maximal $|W|$. As expected, there is a decrease in drop size with increase in aerosol concentration and increase in maximal velocity. Regarding cloud field buoyancy, as predicted, the independent buoyancy cores are more frequently $B_{\mathrm{T}}$ dominated than the dependent buoyancy cores.

The polluted case is populated with dependent cores (white scatter) and shows a classic pre-precipitation convective growth scenario, where relative dominance of the $B_{\mathrm{T}}$ term increases linearly with increase in cloud mean drop size. A logarithmic dependence of $B_{\mathrm{T}}$ dominance on maximal $|W|$ is seen, which saturates at high maximal $|W|$. This can be explained by the fact that increased convection mainly increases the abundance of pixels with $B_{\mathrm{T}}>0$, but without changing the fact that the entire cloud is $B_{\mathrm{Qv}}>0$, so that $B_{\mathrm{T}}$ is unlikely to become the dominant term. The lower concentrations show a more complex scenario. These simulations show a superposition of dependent core convective growth behavior (i.e., the scatter pattern seen for the polluted case) and additional populations of both dependent (other white scatter points) and independent (black scatter) cores.

The independent cores span all the range of possibilities of $B_{\mathrm{T}}$ and $B_{\mathrm{Qv}}$ relative dominance. They tend to have larger cloud mean drop sizes, and a near-zero maximum $|W|$, indicating that they only form at late non-convective stages of cloud development. Furthermore, a trend is seen for the subset of scatter that is $B_{\mathrm{T}}$ dominated, where a positive (negative) correlation between mean drop size (maximal $|W|$ ) and $B_{\mathrm{T}}$ dominance is seen. This again stresses the importance of drop size on the formation of positive buoyancy within downdrafts and highlights the fact that $B_{\mathrm{T}}$ should be largest (and most abundant) below the downdraft equilibrium level, when the $|W|$ approaches zero. The independent cores that are $B_{\mathrm{T}}$ dominated thus fulfill the characteristics of the downdraft buoyancy production process, while the independent cores that are $B_{\mathrm{Qv}}$ dominated may originate from larger clouds (shedding mechanism) with high humidity content, have weak $|W|$, and are slow to evaporate.

The intermediate simulation shows an additional scatter area of dependent core clouds with increasing $B_{\mathrm{T}}$ relative dominance for lower maximal $|W|$, located between the independent core clouds and the convective growth core clouds. These clouds may represent a gradual transition from $B_{\mathrm{Qv}}$ dominance to $B_{\mathrm{T}}$ dominance during dissipation which is only possible in the intermediate simulation. This scatter area is absent from the clean and polluted simulation, in the former case due to absence of the gradual dissipation pathway and in the latter case due to efficient evaporation eliminating $B_{\text {core }}$ during dissipation. We note that the intermediate case shows a slightly higher percentage of clouds that are $B_{\mathrm{T}}$ dominated (see legends in Fig. 8) than the clean case. This can be due to stronger convection in this simulation (i.e., increased $|W|$ range), which favors increased mixing with the dry environment (see Fig. 9) and the formation of unsaturated strong downdrafts that descend below the level of neutral buoyancy. 

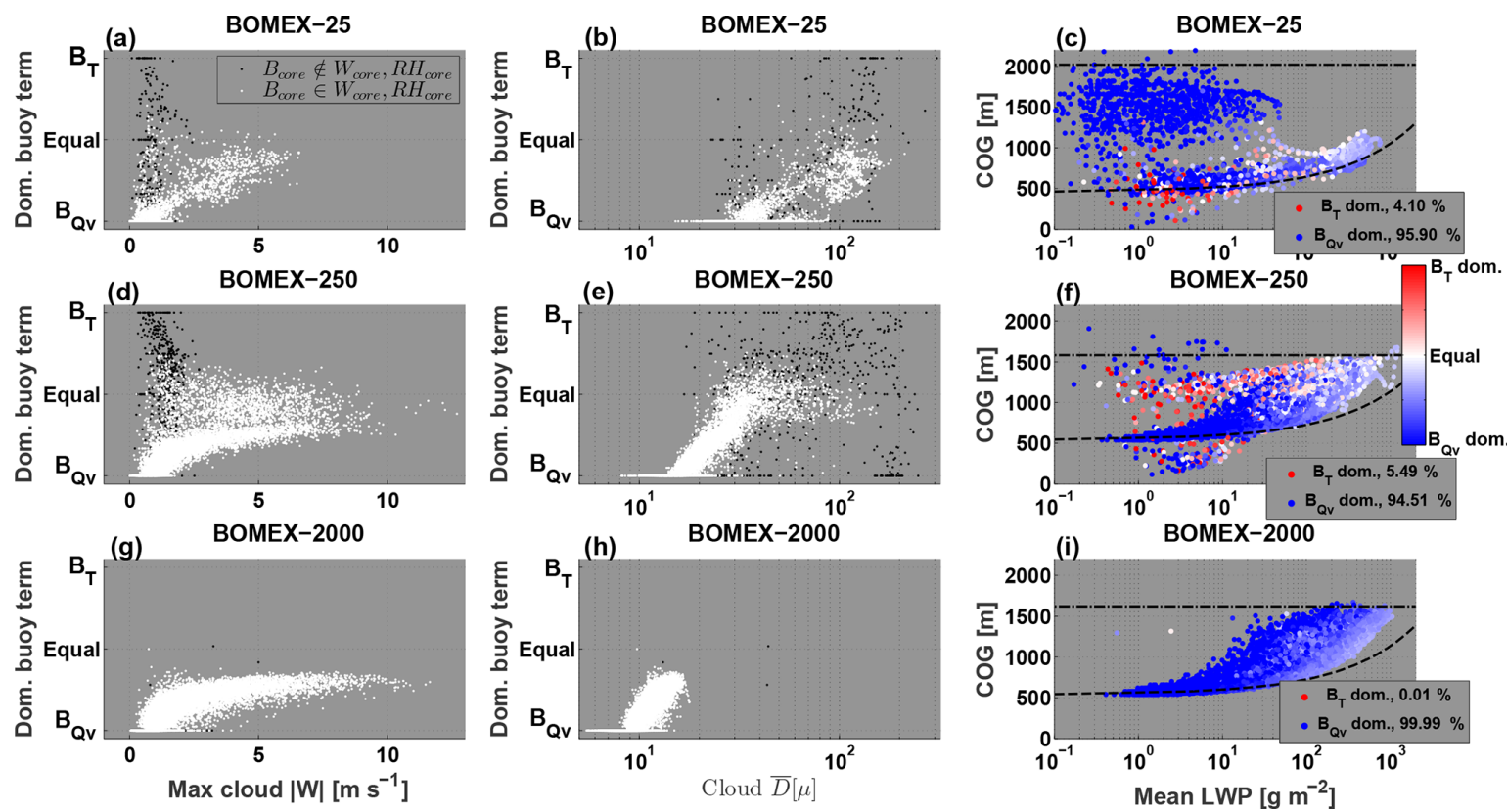

Figure 8. Analyses of dominant buoyancy term within $B_{\text {core }}$ of clouds (see text for details). As seen in previous figures, rows represent clean (top, $\mathbf{a}, \mathbf{b}, \mathbf{c}$ ), intermediate (middle, $\mathbf{d}, \mathbf{e}, \mathbf{f}$ ), and polluted (bottom, $\mathbf{g}, \mathbf{h}, \mathbf{i}$ ) simulations. Columns represent dependence on maximum absolute vertical velocity within cloud (a, d, $\mathbf{g})$, dependence on partition of total cloud mass to cloud droplets and rain drops (b, e, $\mathbf{h})$, and CvM space

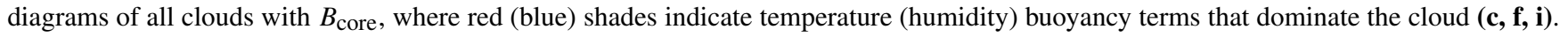
Legends include percentage of clouds that are $B_{\mathrm{T}}$ or $B_{\mathrm{Qv}}$ dominated (see text for explanation).
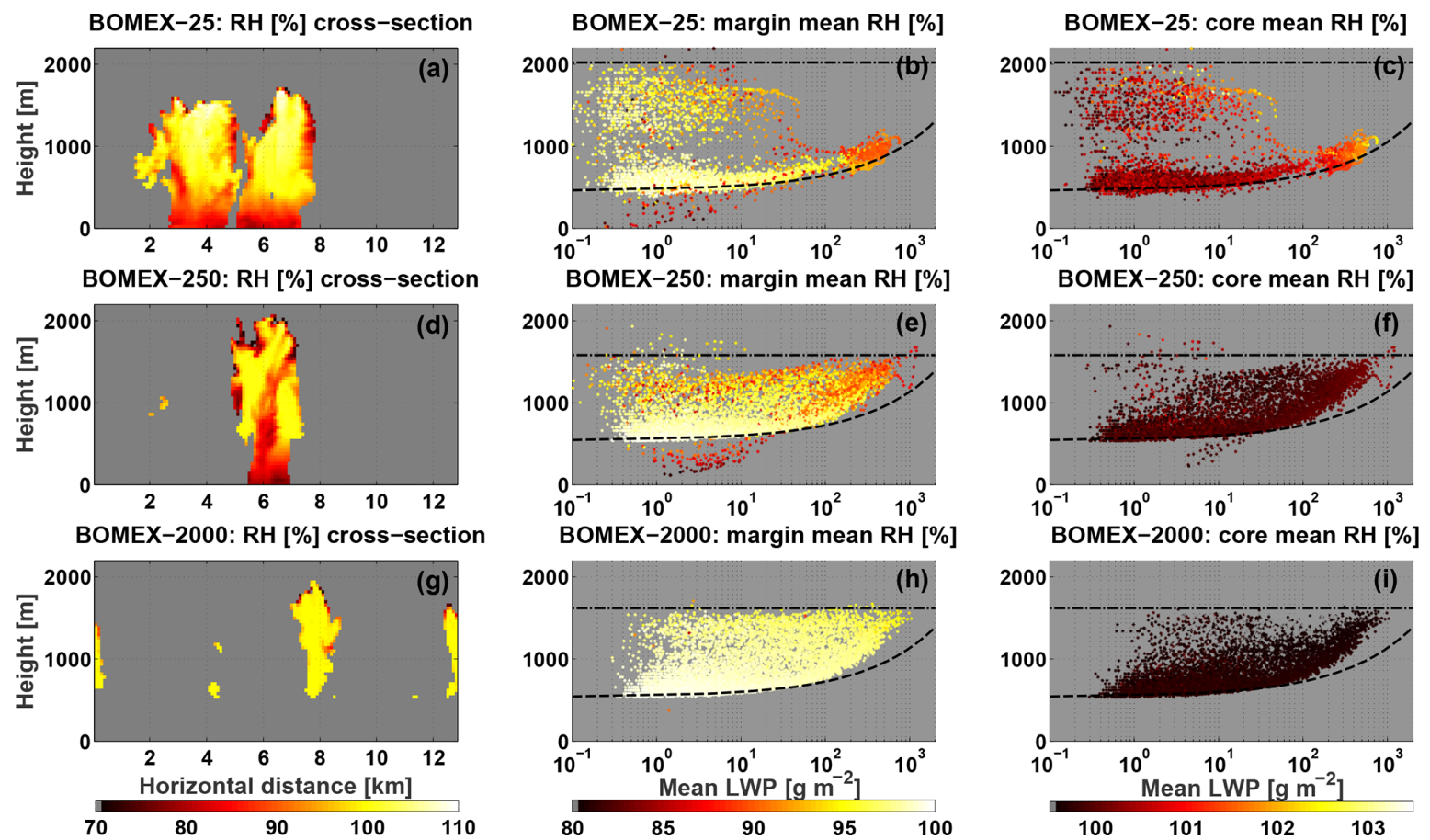

Figure 9. (a, g, g) Relative humidity (RH; \%) vertical cross-sections slicing through the center of gravity of the most massive cloud in each simulation. (b, e, h) and (c, f, i) display CvM space diagrams of mean cloud margin RH and mean cloud core RH, respectively, using the $\mathrm{RH}_{\text {core }}$ definition. The upper $(\mathbf{a}, \mathbf{b}, \mathbf{c})$, middle $(\mathbf{d}, \mathbf{e}, \mathbf{f})$, and lower $(\mathbf{g}, \mathbf{h}, \mathbf{i})$ panels correspond to the clean, intermediate, and polluted aerosol cases. Notice that the different color bar ranges for margin and core mean RH panels. 


\subsection{Aerosol effects on cloud relative humidity}

From Fig. 3 it was demonstrated that a large part of the differences in single cloud characteristics (such as mass, volume, and the partition of these to core and margin regions) due to aerosols can be attributed to differences in vapor diffusion efficiencies. In Fig. 9 we check how these aerosol effects are manifested in the cloud field scale (using the CvM space) by observing the mean $\mathrm{RH}$ in the cloud core and margin of all clouds, where the core (margin) mean RH can be taken as a proxy for condensation (evaporation) efficiency. To gain additional intuition regarding the distribution of $\mathrm{RH}$ values within the clouds, vertical cross-sections (parallel to the prevailing wind direction) of the most massive clouds from each simulation are shown.

The vertical cross-sections demonstrate the large differences in the massive clouds for each of the simulations. In addition to the increase in precipitation production, lower aerosol concentrations yield much larger horizontal extents of clouds. The clean, intermediate, and polluted most massive clouds have a maximum radius of $\sim 3, \sim 1$, and $\sim 0.5 \mathrm{~km}$, respectively. It is clear from the cross-section that the clean cloud is actually composed of two large clouds which merge together. For the clean case, the highest RH values are reached slightly below the cloud top. The edges of the clouds show subsaturation conditions, with the lowest $\mathrm{RH}$ values observed below the lifting condensation level (LCL; precipitation regions) and at the upper interface of the cloud with the environments.

The intermediate-case cloud shows lower maximal and minimal RH values and an increased dominance of the margin region. This cloud penetrates the inversion layer and entrains dry air into the cloud. In addition, the cloud produces significant precipitation which initiates downdrafts of dry entrained air through the cloud center. It can be seen that the increased vertical development of the intermediate-case cloud in comparison with the clean case increases the mixing with the environment. Thus, the dynamic effect of increased mixing and reduction in cloud $\mathrm{RH}$ overcomes the microphysical effect of increased evaporation and increase in cloud $\mathrm{RH}$. The polluted-case cloud, on the other hand, shows a homogeneous RH pattern, with most of the cloud showing around $100 \%$ RH and only a thin layer at the cloud edges (mainly at the upper regions) showing lower RH values. The polluted cloud penetrates the inversion layer as well, but this case lacks precipitation, and the microphysical effect of evaporation overcomes the dynamical effect of mixing.

Keeping in mind the insights obtained from comparisons of individual cloud, we move on to compare the RH characteristics of all clouds within the field. Looking first at core mean $\mathrm{RH}$, a robust decrease is seen with increase in aerosol concentration. This decrease is seen for all cloud types and locations within the CvM space. The polluted case displays the most homogeneous pattern, with all clouds showing core mean $\mathrm{RH}$ values around $100 \%$, indicating efficient consump- tion of the supersaturation. The intermediate case displays a slightly less homogeneous pattern, with values ranging from $100 \%$ to $101 \%$ and with the higher values occurring along the growing cloud branch, especially for the largest clouds. The clean case shows the largest variance in core mean $\mathrm{RH}$, ranging from $100 \%$ for some cloud fragments that soon start to dissipate to $103 \%$ in the cores of the large cloud entities. In addition to the low efficiency in consuming supersaturation, the high RH values in clean large clouds are due to the "protection" by large margin regions surrounding the core region.

The CvM patterns of mean margin $\mathrm{RH}$ show significant differences between the polluted case and the other two. The mean margin $\mathrm{RH}$ values of the polluted case are only marginally lower than $100 \%$, since subsaturated conditions within the cloud are quickly adjusted by efficient evaporation. Only the largest clouds in the polluted case permit lower mean margin $\mathrm{RH}$ values $(\sim 95 \%)$ due to the entrainment of very dry environmental pixels near the cloud tops (as seen in the vertical cross-section as well). The intermediate and clean cases show similar patterns. The smaller mass clouds (both growing and dissipating) show values above $95 \%$, while the larger mass clouds show values as low as $85 \%$. The larger clouds are most likely to reach low-RH areas near the inversion base and below the LCL (i.e., sub-cloudy layer) and entrain dry air and by that reduce the cloud margin $\mathrm{RH}$.

As seen in the vertical cross-section examples, the largest clouds in the intermediate case have even lower margin $\mathrm{RH}$ values than for the clean case. This can be explained by the increased development of the large intermediate clouds to heights with lower RH and by more intense downdrafts for these large clouds. The lowest RH values in the domain are seen for the precipitating fragments (i.e., located below the adiabat). These fragments typically contain low concentrations of large drop sizes (precipitation drops) which are slow to evaporate and capable of surviving in low- $\mathrm{RH}$ conditions within the sub-cloudy layer.

\section{Summary}

In this work we explored how the aerosol effects on warm convective clouds are reflected in their partition to core and margin regions. Following Part 1 of this work (PT1), we evaluated three types of core definitions: positive buoyancy ( $\left.B_{\text {core }}\right)$, supersaturation $\left(\mathrm{RH}_{\text {core }}\right)$, and positive vertical velocity $\left(W_{\text {core }}\right)$. Both single cloud and cloud field models have been used. For all aerosol concentrations (clean, intermediate, and polluted), it is shown that the self-contained property of different core types (i.e., $B_{\text {core }} \subseteq \mathrm{RH}_{\text {core }} \subseteq W_{\text {core }}$ ) is maintained for clouds during their growing and mature stages. This is especially robust for the $\mathrm{RH}_{\text {core }} \subseteq W_{\text {core }}$ subset. The $W_{\text {core }}$ and $\mathrm{RH}_{\text {core }}$ volume fractions decrease monotonically during cloud growth, while $B_{\text {core }}$ initially increases and then decreases after convection ceases. During growth, 
the $\mathrm{RH}_{\text {core }}\left(B_{\text {core }}\right)$ volume fractions are largest for clean (polluted) clouds. This is due to low (high) diffusion efficiencies, respectively, where efficient condensation promotes $B_{\text {core }}$ at the expense of the $\mathrm{RH}_{\text {core }}$.

During dissipation stages cores frequently cease to be subsets of one another and may either increase or decrease in their volume fractions. In cloud fields we also observe small cloud fragments which shed off larger cloud entities. This shedding increases for the lower-concentration simulations which produce long-lived large cloud entities due to cloud merging. These fragments show large variance in volume fraction (for all core types) magnitudes without any consistent behavior. This is due to the fact that they shed off various locations of the cloud. The polluted, non-precipitating cases are unique in that can one expect the $B_{\text {core }}$ to decrease monotonically and remain the smallest and a proper subset of the other cores.

For low aerosol concentrations, a $B_{\text {core }}$ may form during dissipation and exist independently of the other core types. These cores are typically located at the periphery of large clouds or throughout small precipitation or dissipating cloud fragments. The increase in $B_{\text {core }}$ during dissipation typically coincides with large drop sizes and precipitation production. The fluctuations in $B_{\text {core }}$ for low concentrations may also create a subsequent $W_{\text {core }}$ but not of sufficient strength to also create a $\mathrm{RH}_{\text {core }}$. Hence, the $\mathrm{RH}_{\text {core }}$ can be considered the most "well-behaved" and indicative of cloud lifetime, generally monotonically decreasing in volume fraction irrespective of aerosol concentration.

We show that the $B_{\text {core }}$ in the warm convective cases considered here may form by two main processes:

1. Convective updrafts. Adiabatic cooling within updrafts promotes supersaturation, condensation, and release of latent heat. These cores are characterized by both positive temperature $\left(B_{\mathrm{T}}>0\right)$ and humidity $\left(B_{\mathrm{Qv}}>0\right)$ buoyancy terms.

2. Dissipative downdrafts. Subsaturated cloudy downdrafts follow a lapse rate which is unstable relative to the environmental one. These downdrafts undershoot the equilibrium level and become positively buoyant. These cores are characterized by positive temperature $\left(B_{\mathrm{T}}>\right.$ 0 ) but neutral humidity $\left(B_{\mathrm{Qv}} \sim 0\right.$ ) buoyancy terms.

The updraft buoyancy type is seen for all aerosol concentrations, while the dissipation buoyancy type is only seen for lower aerosol concentrations. The fact that the downdraft $B_{\text {core }}$ is absent from polluted clouds highlights the importance of drop size and its effect on evaporation rate. The high (low) diffusion (collision coalescence) efficiencies in polluted clouds maintain a small mean drop size and enable rapid evaporation during entrainment, causing a negative effect on buoyancy. For lower concentrations, clouds with a downdraft $B_{\text {core }}$ that only exist during late mature, dissipation, and precipitating stages after drop size have grown considerably. The larger mean drop sizes reduce evaporation rates, and the cloudy downdrafts may thus descend nearly dry adiabatically and become positively buoyant.

Focusing on cores using the RH definition, a cloud's mass (volume) is dependent primarily on the processes in its core (margin). The core increases cloud mass by condensation while the margin increases the cloud's volume by mixing with the environment or dilution. The magnitude of the effects in each region of the cloud is strongly dependent on the aerosol concentration. Polluted clouds are core dominated both in terms of mass and volume, since they can hardly maintain their margins. Clean clouds are also core dominated in terms of mass but to a lesser degree. Clean clouds tend to be margin dominated in terms of volume for most their lifetimes. Thus, despite weaker convection in the clean clouds, their large, slow evaporating margins enable their cores (and the entire cloud) to exist for longer time spans by applying a large protecting shield around the core.

The different diffusion efficiencies are demonstrated by observing the relative humidity $(\mathrm{RH})$ values in clouds. Cleaner clouds show larger variance in RH values. During their growing stages large supersaturation in the core and subsaturation in the margin can be seen. During their dissipation stages clouds may exist for minutes without any cloud core, with the entire cloud at subsaturation. Polluted clouds show the opposite, with RH values nearing $100 \%$ throughout the cloud at all stages. Hence, above a certain aerosol concentration, the saturation adjustment approximation (i.e., instant condensation of all supersaturation) can be considered valid. However, the transition from clean to polluted is not always linear. For example, the largest clouds in the intermediate case have a lower margin $\mathrm{RH}$ value than both the clean and polluted cases. This is due to the fact that the intermediate case manages to develop taller (than the clean case) clouds with stronger updrafts and downdrafts, which entrain drier air from above the inversion layer base, but at the same time is less efficient in evaporating (than the polluted case) water and adjusting the RH to $100 \%$.

Data availability. The microphysical and thermodynamical profiles used to initialize the single cloud and cloud field numerical simulations can be obtained upon request from the corresponding author.

Author contributions. RHH ran the cloud field simulations, conducted the analyses, and wrote the final draft of paper. LP participated in writing the first draft and performed single cloud simulations and relevant analyses. OA, GD, and IK participated in paper editing and discussions.

Competing interests. The authors declare that they have no conflict of interest. 
Acknowledgements. The authors would like to acknowledge the Weizmann Institute High Performance Computing (HPC) team for their support.

Financial support. The research leading to these results was supported by the Ministry of Science and Technology, Israel (grant no. 3-14444).

Review statement. This paper was edited by Eric Jensen and reviewed by two anonymous referees.

\section{References}

Albrecht, B. A.: Aerosols, cloud microphysics, and fractional cloudiness, Science, 245, 1227-1230, https://doi.org/10.1126/science.245.4923.1227, 1989.

Altaratz, O., Koren, I., Reisin, T., Kostinski, A., Feingold, G., Levin, Z., and Yin, Y.: Aerosols' influence on the interplay between condensation, evaporation and rain in warm cumulus cloud, Atmos. Chem. Phys., 8, 15-24, https://doi.org/10.5194/acp-8-15-2008, 2008.

Altaratz, O., Koren, I., Remer, L. A., and Hirsch, E.: Review: Cloud invigoration by aerosols - Coupling between microphysics and dynamics, Atmos. Res., 140-141, 38-60, https://doi.org/10.1016/j.atmosres.2014.01.009, 2014.

Andreae, M. O., Rosenfeld, D., Artaxo, P., Costa, A. A., Frank, G. P., Longo, K. M., and Silva-Dias, M. A. F.: Smoking rain clouds over the Amazon, Science, 303, 1337-1342, https://doi.org/10.1126/science.1092779, 2004.

Betts, A. K.: Saturation point analysis of moist convective overturning, J. Atmos. Sci., 39, 1484-1505, https://doi.org/10.1175/15200469(1982)039<1484:SPAOMC>2.0.CO;2, 1982.

Betts, A. K. and Silva Dias, M. F.: Unsaturated downdraft thermodynamics in cumulonimbus, J. Atmos. Sci., 36, 1061-1071, https://doi.org/10.1175/15200469(1979)036<1061:UDTIC>2.0.CO;2, 1979.

Carrió, G. G. and Cotton, W. R.: On the buffering of $\mathrm{CCN}$ impacts on wintertime orographic clouds: An idealized examination, Atmos. Res., 137, 136-144, https://doi.org/10.1016/j.atmosres.2013.09.011, 2014.

Dagan, G., Koren, I., and Altaratz, O.: Aerosol effects on the timing of warm rain processes, Geophys. Res. Lett., 42, 4590-4598, https://doi.org/10.1002/2015GL063839, 2015a.

Dagan, G., Koren, I., and Altaratz, O.: Competition between core and periphery-based processes in warm convective clouds - from invigoration to suppression, Atmos. Chem. Phys., 15, 27492760, https://doi.org/10.5194/acp-15-2749-2015, 2015b.

Dagan, G., Koren, I., Altaratz, O., and Heiblum, R. H.: Aerosol effect on the evolution of the thermodynamic properties of warm convective cloud fields, Sci. Rep.-UK, 6, 38769, https://doi.org/10.1038/srep38769, 2016.

Dagan, G., Koren, I., Altaratz, O., and Heiblum, R. H.: Timedependent, non-monotonic response of warm convective cloud fields to changes in aerosol loading, Atmos. Chem. Phys., 17, 7435-7444, https://doi.org/10.5194/acp-17-7435-2017, 2017.
Dey, S., Di Girolamo, L., Zhao, G., Jones, A. L., and McFarquhar, G. M.: Satellite-observed relationships between aerosol and trade-wind cumulus cloud properties over the Indian Ocean, Geophys. Res. Lett., 38, L01804, https://doi.org/10.1029/2010GL045588, 2011.

Glassmeier, F. and Lohmann, U.: Precipitation Susceptibility and Aerosol Buffering of Warm- and Mixed-Phase Orographic Clouds in Idealized Simulations, J. Atmos. Sci., 75, 1173-1194, https://doi.org/10.1175/JAS-D-17-0254.1, 2018.

Grant, L. D. and van den Heever, S. C.: Cold pool and precipitation responses to aerosol loading: modulation by dry layers, J. Atmos. Sci., 72, 1398-1408, https://doi.org/10.1175/JAS-D-140260.1, 2015.

Heiblum, R. H., Altaratz, O., Koren, I., Feingold, G., Kostinski, A. B., Khain, A. P., Ovchinnikov, M., Fredj, E., Dagan, G., Pinto, L., Yaish, R., and Chen, Q.: Characterization of cumulus cloud fields using trajectories in the center of gravity versus water mass phase space: 1 . Cloud tracking and phase space description, J. Geophys. Res.-Atmos., 121, 6336-6355, https://doi.org/10.1002/2015JD024186, 2016a.

Heiblum, R. H., Altaratz, O., Koren, I., Feingold, G., Kostinski, A. B., Khain, A. P., Ovchinnikov, M., Fredj, E., Dagan, G., Pinto, L., Yaish, R., and Chen, Q.: Characterization of cumulus cloud fields using trajectories in the center of gravity versus water mass phase space: 2. Aerosol effects on warm convective clouds, J. Geophys. Res.-Atmos., 121, 6356-6373, https://doi.org/10.1002/2015JD024193, 2016b.

Heiblum, R. H., Pinto, L., Altaratz, O., Dagan, G., and Koren, I.: Core and margin in warm convective clouds - Part 1: Core types and evolution during a cloud's lifetime, Atmos. Chem. Phys., 19, 10717-10738, https://doi.org/10.5194/acp-19-107172019, 2019.

Hudson, J. G. and Mishra, S.: Relationships between CCN and cloud microphysics variations in clean maritime air, Geophys. Res. Lett., 34, L16804, https://doi.org/10.1029/2007GL030044, 2007.

Hudson, J. G. and Yum, S. S.: Maritime-continental drizzle contrasts in small cumuli, J. Atmos. Sci., 58, 915-926, https://doi.org/10.1175/15200469(2001)058<0915:MCDCIS>2.0.CO;2, 2001.

Igau, R. C., LeMone, M. A., and Wei, D.: Updraft and downdraft cores in TOGA COARE: why so many buoyant downdraft cores?, J. Atmos. Sci., 56, 2232-2245, https://doi.org/10.1175/15200469(1999)056<2232:UADCIT>2.0.CO;2, 1999.

IPCC: Climate Change 2013: The Physical Science Basis. Working Group I Contribution to the Fifth Assessment Report of the IPCC, Cambridge Univ. Press, New York, 2013.

Jaenicke, R.: 9.3.1 Physical properties, in: Physical and chemical properties of the air, edited by: Fischer, G., 405-420, SpringerVerlag, Berlin/Heidelberg, 1988.

Jiang, H. and Feingold, G.: Effect of aerosol on warm convective clouds: Aerosol-cloud-surface flux feedbacks in a new coupled large eddy model, J. Geophys. Res., 111, D01202, https://doi.org/10.1029/2005JD006138, 2006.

Jiang, H., Xue, H., Teller, A., Feingold, G., and Levin, Z.: Aerosol effects on the lifetime of shallow cumulus, Geophys. Res. Lett. 33, L14806, https://doi.org/10.1029/2006GL026024, 2006. 
Jiang, H., Feingold, G., and Koren, I.: Effect of aerosol on trade cumulus cloud morphology, J. Geophys. Res., 114, D11209, https://doi.org/10.1029/2009JD011750, 2009.

Kaufman, Y. J., Koren, I., Remer, L. A., Rosenfeld, D., and Rudich, Y.: The effect of smoke, dust, and pollution aerosol on shallow cloud development over the Atlantic Ocean, P. Natl. Acad. Sci. USA, 102, 11207-11212, https://doi.org/10.1073/pnas.0505191102, 2005.

Khain, A., Pokrovsky, A., Pinsky, M., Seifert, A., and Phillips, V.: Simulation of Effects of Atmospheric Aerosols on Deep Turbulent Convective Clouds Using a Spectral Microphysics Mixed-Phase Cumulus Cloud Model. Part I: Model Description and Possible Applications, J. Atmos. Sci., 61, 2963-2982, https://doi.org/10.1175/JAS-3350.1, 2004.

Khain, A., Rosenfeld, D., and Pokrovsky, A.: Aerosol impact on the dynamics and microphysics of deep convective clouds, Q. J. Roy. Meteor. Soc., 131, 2639-2663, https://doi.org/10.1256/qj.04.62, 2005.

Khain, A. P., BenMoshe, N., and Pokrovsky, A.: Factors Determining the Impact of Aerosols on Surface Precipitation from Clouds: An Attempt at Classification, J. Atmos. Sci., 65, 1721-1748, https://doi.org/10.1175/2007JAS2515.1, 2008.

Khairoutdinov, M. F. and Randall, D. A.: Cloud resolving modeling of the ARM summer 1997 IOP: model formulation, results, uncertainties, and sensitivities, J. Atmos. Sci., 60, 607-625, https://doi.org/10.1175/15200469(2003)060<0607:CRMOTA>2.0.CO;2, 2003.

Knupp, K. R. and Cotton, W. R.: Convective cloud downdraft structure: An interpretive survey, Rev. Geophys., 23, 183, https://doi.org/10.1029/RG023i002p00183, 1985.

Kogan, Y. L. and Martin, W. J.: Parameterization of bulk condensation in numerical cloud models, J. Atmos. Sci., 51, 1728-1739, https://doi.org/10.1175/15200469(1994)051<1728:POBCIN>2.0.CO;2, 1994.

Köhler, H.: The nucleus in and the growth of hygroscopic droplets, T. Faraday Soc., 32, 1152-1161, 1936.

Koren, I., Dagan, G., and Altaratz, O.: From aerosol-limited to invigoration of warm convective clouds, Science, 344, 1143-1146, https://doi.org/10.1126/science.1252595, 2014.

Koren, I., Altaratz, O., and Dagan, G.: Aerosol effect on the mobility of cloud droplets, Environ. Res. Lett., 10, 104011, https://doi.org/10.1088/1748-9326/10/10/104011, 2015.

L'Ecuyer, T. S., Berg, W., Haynes, J., Lebsock, M., and Takemura, T.: Global observations of aerosol impacts on precipitation occurrence in warm maritime clouds, J. Geophys. Res., 114, D09211, https://doi.org/10.1029/2008JD011273, 2009.

Li, Z., Niu, F., Fan, J., Liu, Y., Rosenfeld, D., and Ding, Y.: Long-term impacts of aerosols on the vertical development of clouds and precipitation, Nat. Geosci., 4, 888-894, https://doi.org/10.1038/ngeo1313, 2011.

Mason, B. J. and Chien, C. W.: Cloud-droplet growth by condensation in cumulus, Q. J. Roy. Meteor. Soc., 88, 136-142, 1962.

Mordy, W.: Computations of the growth by condensation of a population of cloud droplets, Tellus, 11, 16-44, https://doi.org/10.1111/j.2153-3490.1959.tb00003.x, 1959.

Paluch, I. R. and Breed, D. W.: A Continental Storm with a Steady, Adiabatic Updraft and High Concentrations of Small Ice Particles: 6 July 1976 Case Study, J. At- mos. Sci., 41, 1008-1024, https://doi.org/10.1175/15200469(1984)041<1008:ACSWAS>2.0.CO;2, 1984.

Pinsky, M., Mazin, I. P., Korolev, A., and Khain, A.: Supersaturation and diffusional droplet growth in liquid clouds, J. Atmos. Sci., 70, 2778-2793, https://doi.org/10.1175/JAS-D-12-077.1, 2013.

Reisin, T., Levin, Z., and Tzivion, S.: Rain Production in Convective Clouds As Simulated in an Axisymmetric Model with Detailed Microphysics. Part I: Description of the Model, J. Atmos. Sci., 53, 497-519, https://doi.org/10.1175/15200469(1996)053<0497:RPICCA>2.0.CO;2, 1996.

Reutter, P., Su, H., Trentmann, J., Simmel, M., Rose, D., Gunthe, S. S., Wernli, H., Andreae, M. O., and Pöschl, U.: Aerosol- and updraft-limited regimes of cloud droplet formation: influence of particle number, size and hygroscopicity on the activation of cloud condensation nuclei (CCN), Atmos. Chem. Phys., 9, 70677080, https://doi.org/10.5194/acp-9-7067-2009, 2009.

Saleeby, S. M., Herbener, S. R., van den Heever, S. C., and L'Ecuyer, T.: Impacts of cloud droplet-nucleating aerosols on shallow tropical convection, J. Atmos. Sci., 72, 1369-1385, https://doi.org/10.1175/JAS-D-14-0153.1, 2015.

Savane, O., Vant-Hull, B., Mahani, S., and Khanbilvardi, R.: Effects of aerosol on cloud liquid water path: statistical method a potential source for divergence in past observation based correlative studies, Atmosphere, 6, 273-298, https://doi.org/10.3390/atmos6030273, 2015.

Seifert, A. and Heus, T.: Large-eddy simulation of organized precipitating trade wind cumulus clouds, Atmos. Chem. Phys., 13, 5631-5645, https://doi.org/10.5194/acp-13-5631-2013, 2013.

Seifert, A., Heus, T., Pincus, R., and Stevens, B.: Large-eddy simulation of the transient and near-equilibrium behavior of precipitating shallow convection, J. Adv. Model. Earth Sy., 7, 19181937, https://doi.org/10.1002/2015MS000489, 2015.

Seigel, R. B.: Shallow Cumulus Mixing and Subcloud-Layer Responses to Variations in Aerosol Loading, J. Atmos. Sci., 71, 2581-2603, https://doi.org/10.1175/JAS-D-13-0352.1, 2014.

Seiki, T. and Nakajima, T.: Aerosol effects of the condensation process on a convective cloud simulation, J. Atmos. Sci., 71, 833853, https://doi.org/10.1175/JAS-D-12-0195.1, 2014.

Sheffield, A. M., Saleeby, S. M., and van den Heever, S. C.: Aerosol-induced mechanisms for cumulus congestus growth, J. Geophys. Res.-Atmos., 120, 8941-8952, https://doi.org/10.1002/2015JD023743, 2015.

Siebesma, A. P., Bretherton, C. S., Brown, A., Chlond, A., Cuxart, J., Duynkerke, P. G., Jiang, H., Khairoutdinov, M., Lewellen, D., Moeng, C.-H., Sanchez, E., Stevens, B., and Stevens, D. E.: A large eddy simulation intercomparison study of shallow cumulus convection, J. Atmos. Sci., 60, 1201-1219, https://doi.org/10.1175/15200469(2003)60<1201:ALESIS>2.0.CO;2, 2003.

Small, J. D., Chuang, P. Y., Feingold, G., and Jiang, H.: Can aerosol decrease cloud lifetime?, Geophys. Res. Lett., 36, https://doi.org/10.1029/2009GL038888, 2009.

Sorooshian, A., Feingold, G., Lebsock, M. D., Jiang, H., and Stephens, G. L.: On the precipitation susceptibility of clouds to aerosol perturbations, Geophys. Res. Lett., 36, L13803, https://doi.org/10.1029/2009GL038993, 2009.

Squires, P.: The microstructure and colloidal stability of warm clouds, Tellus, 10, 256-261, https://doi.org/10.1111/j.21533490.1958.tb02011.x, 1958. 
Stevens, B.: On the growth of layers of nonprecipitating cumulus convection, J. Atmos. Sci., 64, 2916-2931, https://doi.org/10.1175/JAS3983.1, 2007.

Stevens, B. and Feingold, G.: Untangling aerosol effects on clouds and precipitation in a buffered system, Nature, 461, 607-613, https://doi.org/10.1038/nature08281, 2009.

Storer, R. L. and van den Heever, S. C.: Microphysical processes evident in aerosol forcing of tropical deep convective clouds, J. Atmos. Sci., 70, 430-446, https://doi.org/10.1175/JAS-D-12-076.1, 2013.

Twomey, S.: The influence of pollution on the shortwave albedo of clouds, J. Atmos. Sci., 34, 1149-1152, https://doi.org/10.1175/15200469(1977)034<1149:TIOPOT>2.0.CO;2, 1977.

Tzivion, S., Feingold, G., and Levin, Z.: An efficient numerical solution to the stochastic collection equation, J. Atmos. Sci., 44, 3139-3149, https://doi.org/10.1175/15200469(1987)044<3139:AENSTT>2.0.CO;2, 1987.

Wang, C.: A modeling study of the response of tropical deep convection to the increase of cloud condensation nuclei concentration: 1. Dynamics and microphysics, J. Geophys. Res., 110, D21211, https://doi.org/10.1029/2004JD005720, 2005.

Warner, J.: A Reduction in Rainfall Associated with Smoke from Sugar-Cane Fires - An Inadvertent Weather Modification?, J. Appl. Meteorol., 7, 247-251, https://doi.org/10.1175/15200450(1968)007<0247:ARIRAW>2.0.CO;2, 1968
Wei, D., Blyth, A. M., and Raymond, D. J.: Buoyancy of convective clouds in TOGA COARE, J. Atmos. Sci., 55, 3381-3391, https://doi.org/10.1175/15200469(1998)055<3381:BOCCIT>2.0.CO;2, 1998.

$\mathrm{Xu}$, K.-M. and Randall, D. A.: Updraft and downdraft statistics of simulated tropical and midlatitude cumulus convection, J. Atmos. Sci., 58, 1630-1649, https://doi.org/10.1175/15200469(2001)058<1630:UADSOS>2.0.CO;2, 2001.

Xue, H. and Feingold, G.: Large-Eddy Simulations of Trade Wind Cumuli: Investigation of Aerosol Indirect Effects, J. Atmos. Sci., 63, 1605-1622, https://doi.org/10.1175/JAS3706.1, 2006.

Xue, H., Feingold, G., and Stevens, B.: Aerosol effects on clouds, precipitation, and the organization of shallow cumulus convection, J. Atmos. Sci., 65, 392-406, https://doi.org/10.1175/2007JAS2428.1, 2008.

Yuan, T., Remer, L. A., and Yu, H.: Microphysical, macrophysical and radiative signatures of volcanic aerosols in trade wind cumulus observed by the A-Train, Atmos. Chem. Phys., 11, 71197132, https://doi.org/10.5194/acp-11-7119-2011, 2011.

Zhao, M. and Austin, P. H.: Life cycle of numerically simulated shallow cumulus clouds. part I: transport, J. Atmos. Sci., 62, 1269-1290, https://doi.org/10.1175/JAS3414.1, 2005a.

Zhao, M. and Austin, P. H.: Life cycle of numerically simulated shallow cumulus clouds. part II: mixing dynamics, J. Atmos. Sci., 62, 1291-1310, https://doi.org/10.1175/JAS3415.1, 2005 b. 